\title{
Tribology of the wheel-rail contact - aspects of wear, particle emission and adhesion
}

\author{
Ulf Olofsson ${ }^{1}$ Yi Zhu ${ }^{1}$ Saeed Abbasi ${ }^{1}$ Roger Lewis ${ }^{2}$ Stephen Lewis ${ }^{2}$ \\ Department of Machine Design KTH Stockholm Sweden \\ Department of Mechanical Engineering, Sheffield University, UK
}

\begin{abstract}
The wheel-rail contact is a safety critical interface. Wear, particle emission and adhesion are all wheelrail contact phenomena and are discussed here. All three phenomena are material and system parameters and are linked together. Different countermeasures to one phenomenon such as adhesion enhancement with a friction modifier can increase the wear in the contacting bodies. The wear of railway wheel and rail are linked to the number of airborne particles generated, but the exact number and size distribution of the aerosols is unknown. The main objective of this study is to review recent work in this field and to discuss future trends.
\end{abstract}

Keywords

Wheel-rail, wear, particle emission, adhesion, airborne particles

\section{Introduction}

In the tiny contact zone (roughly $1 \mathrm{~cm}^{2}$ ) where steel wheel meets steel rail the contact forces that carry the load and roll of the train are transmitted. As will be presented here the wheel-rail contact is extremely complex. A broad interdisciplinary approach is needed to understand, model and optimise it. The contact is absolutely critical to the safe and efficient operation of a railway network. A lot of the complexity of the wheel-rail contact is brought about by the open nature of the system and the constantly varying environmental conditions in terms of for instance temperature and humidity. This is exemplified in the relationship between weather conditions and measured rail wear shown in Figure 1. Here the precipitation had a significant effect on rail wear. Along a length of line the position of the contact and its size and the resulting contact stresses are also continuously varying and will be different, not just for each railway vehicle, but for each wheel as each, although starting with the same profile, will have worn by different amounts. An example of the change of wheel and rail profiles over a two year period in Stockholm local traffic can be seen in Figure 2. Since the wheel-rail contact is an open system, damage mechanisms, such as wear and rolling contact fatigue, will be influenced by factors such as humidity and other natural contaminants. They will also be affected by third body material applied positively to the contact to control friction and wear. 


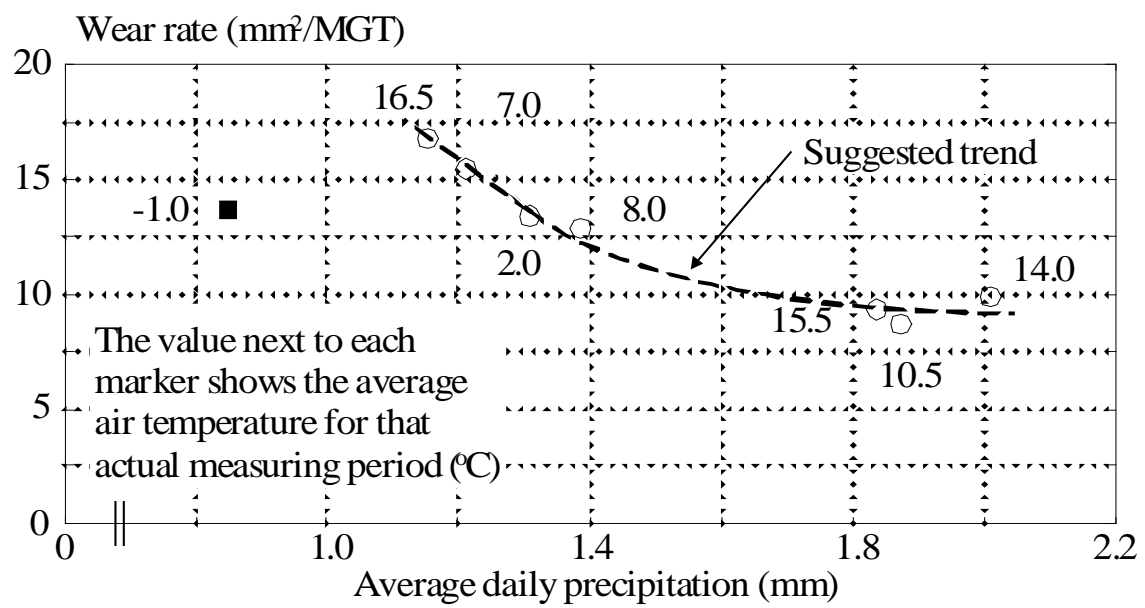

Figure 1. Rail wear rate versus average daily precipitation, from Nilsson [1]. MGT = mega gross tonne traffic. Note also the outlier at low temperature.

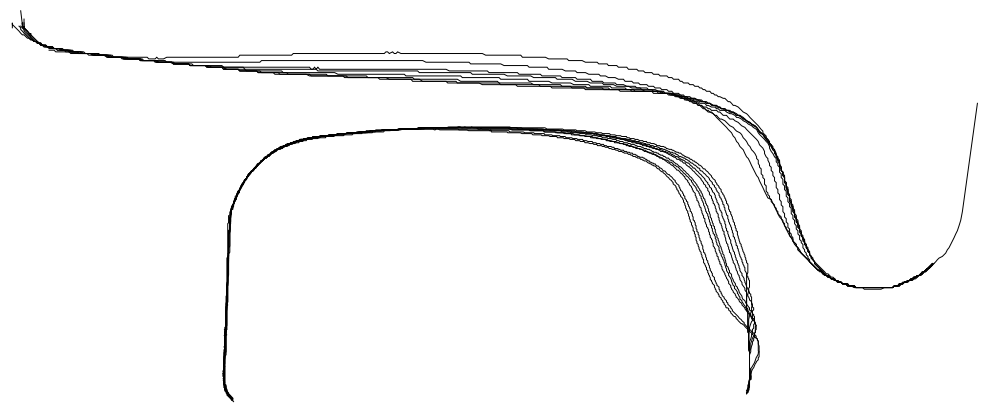

Figure 2. Form change of wheel and rail over a two year period from the Stockholm test case, (UIC60 standard rail profile and the wheel profile from X10 powered vehicles) Nilsson [1].

Wear, particle emission and adhesion are all wheel-rail contact phenomena and are covered in this paper. Wear can be defined as the loss of material from a surface, as exemplified in Figure 2, while particle emissions can be aerosols generated from a wear process such as those that occur in the wheelrail contact. In a railway context, "adhesion" can be used to define the friction that can be made available to transfer tangential forces between a driving railway wheel and the rail. Sometimes "traction" is used for a driving wheel and "adhesion" is used for a braking wheel, but in this document "adhesion" is used for both situations. The available adhesion is limited by the coefficient of friction. If a driving railway wheel applies a tangential force larger than this limit, the wheel will slip causing severe wear damage to the rail.

\section{Wear}

The profile change of rail on curves makes a large contribution to track maintenance costs. The profile change on wheels can also be significant, especially on a curved track. Damage mechanisms such as wear and plastic deformation are the main contributors to profile change.

\subsection{Wear mechanisms}

Wear is the loss or displacement of material from a contacting surface. Material loss may be in the form of debris. Material displacement may occur by transfer of material from one surface to another

This paper was published in Vehicle System Dynamics; Special Issue: State of Art Papers of the $23^{\text {rd }}$ IAVSD in 2013. Online version: http://dx.doi.org/10.1080/00423114.2013.800215 
by adhesion or by local plastic deformation. There are many different wear mechanisms that can occur between contacting bodies each of them producing different wear rates. The simplest classification of the different types of wear that produce different wear rates is "mild wear" and "severe wear". Mild wear results in a smooth surface that often is smoother than the original surface. On the other hand, severe wear results in a rough surface that often is rougher than the original surface [2]. Mild wear is a form of wear characterised by the removal of materials in very small fragments. Mild wear is favourable in many cases for the wear life of the contact as it causes a smooth run-in of the contacting surfaces. However, in some cases it has been observed that it worsens the contact condition and the mild wear can change the form of the contacting surfaces in an unfavourable way [3]. Another wear process that results in a smooth surface is the oxidative wear processes characterised by the removal of the oxide layer on the contacting surfaces. In this case the contact temperature and asperity level influence the wear rate [4]. Abrasive wear caused by hard particles between the contacting surfaces can also cause significant wear and reduce the life of the contacting bodies [5].

The basic concept for adhesive mechanisms is that actual contact between surfaces occurs at discrete points within the apparent area of contact. At these spots, called junctions, bonding occurs between surface asperities (see Figure 3). When the surfaces move relative to each other, these junctions are broken and new ones formed. Usually the tip is plucked off the softer asperity leaving them adhering to the harder surface. This can be via a ductile or brittle fracture. Subsequently the tips become loose and give rise to wear debris. Severe damage can sometimes result in the tearing away of macroscopic chunks of material and this situation is known as galling. If adhesive wear results from the breakdown of lubrication in a contact then the term scuffing is used to describe the onset of wear.

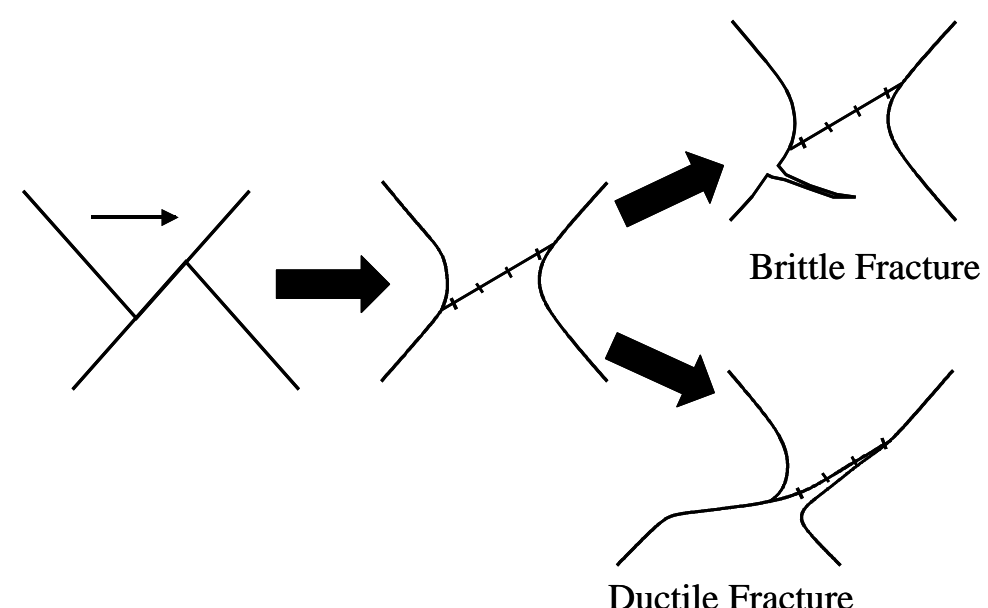

Figure 3. Adhesive wear mechanisms.

Abrasive wear is damage to a component surface, which arises because of the motion relative to that surface of either harder asperities (two-body abrasive wear) or because of hard particles trapped between the surfaces (three-body abrasive wear) (see Figure 4). Such particles may be introduced between the two softer surfaces as a contaminant from the outside environment, or they may have been formed in situ by oxidation or by some other chemical or mechanical process. 


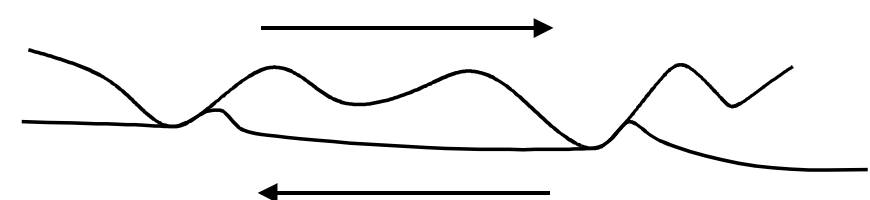

Two-Body Abrasive Wear

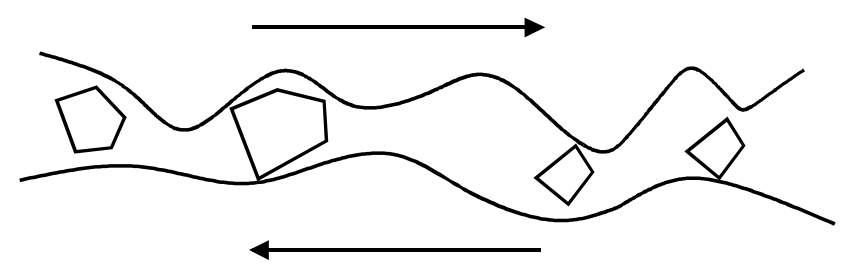

Three-Body Abrasive Wear

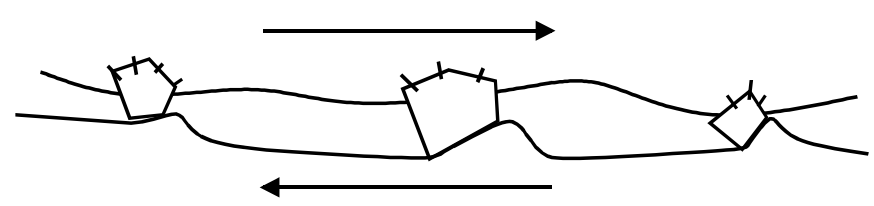

Two-Body Abrasive Wear, with Embedded Particles

Figure 4. Abrasive wear mechanisms.

The rate of damage is relatively insensitive to the hardness of the particles in a three-body situation, as long as they are at least $20 \%$ harder than the surface itself. The most commonly occurring contaminant in industrial machinery is that from quartz or silica (these minerals make up about $60 \%$ of the Earth's crust) (silica sand is either used on its own as a friction enhancer in the wheel-rail contact or mixed with water and viscosity enhancer in traction gels such as Sandite or Alleviate). These are likely to have hardness is excess of 8GPa and consequently do damage to even hardened steels (typically of hardness 7-8GPa).

The oxidative wear process involves the formation of oxides on the surface of the material. It is clearly related to the ability of the wearing material to undergo oxidation and the availability of oxygen. Whether it occurs depends on the temperatures generated in the contact and the relative humidity. Wear rates are lower than those seen with mechanical wear processes. The material removal process is illustrated in Figure 5, as well as the surface of a wheel disc from a twin disc test run under relatively mild contact conditions, where it can be seen that platelets of oxidised material have broken away from the surface.
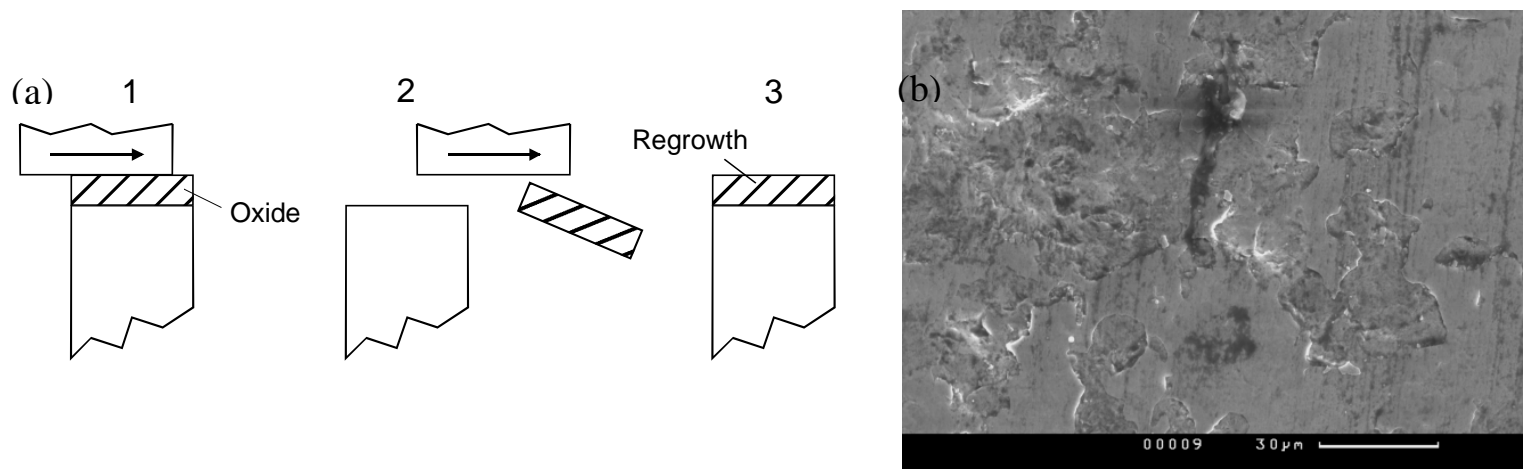

Figure 5. Oxidative wear (a) wear process and (b) typical surface morphology. 
Thermal wear processes are those directly associated with the increase in temperature caused by frictional heating in the contact. The principal type of wear process in this category is when a material melts or softens to such an extent that it can be displaced like a viscous fluid. Other mechanisms, such as adhesive wear, are also accelerated by a reduction in hardness. Other types are linked with thermal stresses that can cause thermal fatigue and cracking, which lead to loss of material.

\subsection{Wear rates and wear mapping}

Wear is often classified as being mild or severe. This is not based on any particular numerical value of wear rate, but on the general observation that for any pair of materials, increasing the severity of the loading (e.g. by increasing either the normal load, sliding speed or bulk temperature) leads at some stage to a comparatively sudden jump in the wear rate.

The mechanisms most associated with severe wear are adhesive or thermal mechanisms. Increasing temperatures in the contact and the resulting thermal softening can lead to a further transition in to a catastrophic wear regime.

The three wear regimes outlined above have been seen during rolling/sliding laboratory tests on wheel and rail materials, as shown in Figure 6 for R8T wheel material.

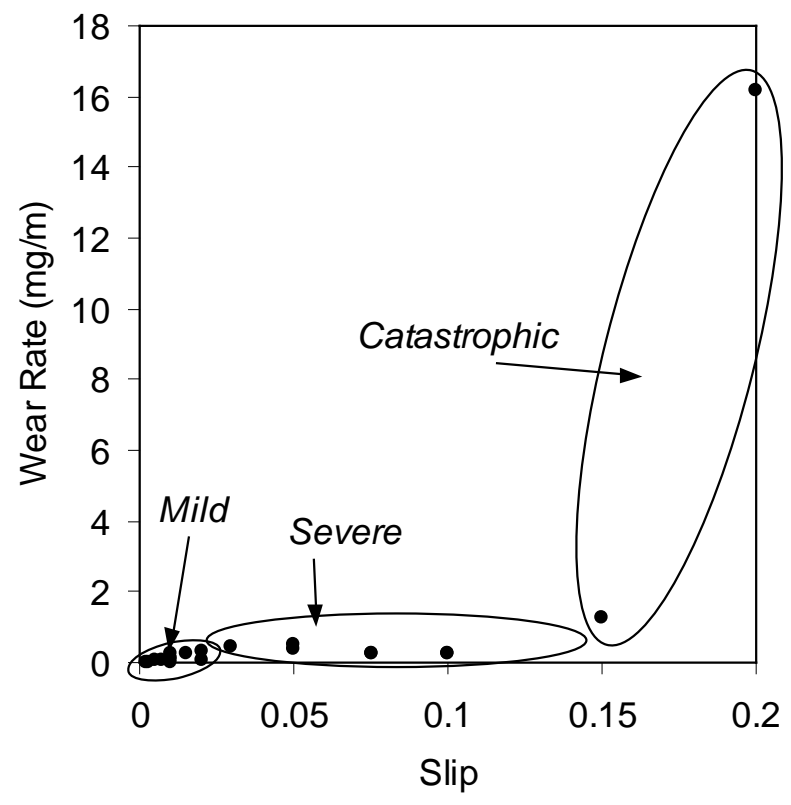

Figure 6. Wear rates of R8T wheel material using a twin disc rolling/sliding test (Lewis \& DwyerJoyce [6]).

A good way of displaying wear data is a map, as first illustrated in Figure 7. The map below is for a wheel-rail contact (Lewis \& Olofsson, [7]). The wear data was built up using a mixture of twin disc and pin-on-disc testing methods using R7 wheel material and UIC 60 900A rail material. The map has been laid over some predicted wheel-rail contact conditions. As can be seen the wheel tread/rail head contact falls in the mild to severe wear regime and the wheel flange/rail gauge corner contact is in the severe to catastrophic regimes. This matches what is seen in the field. 


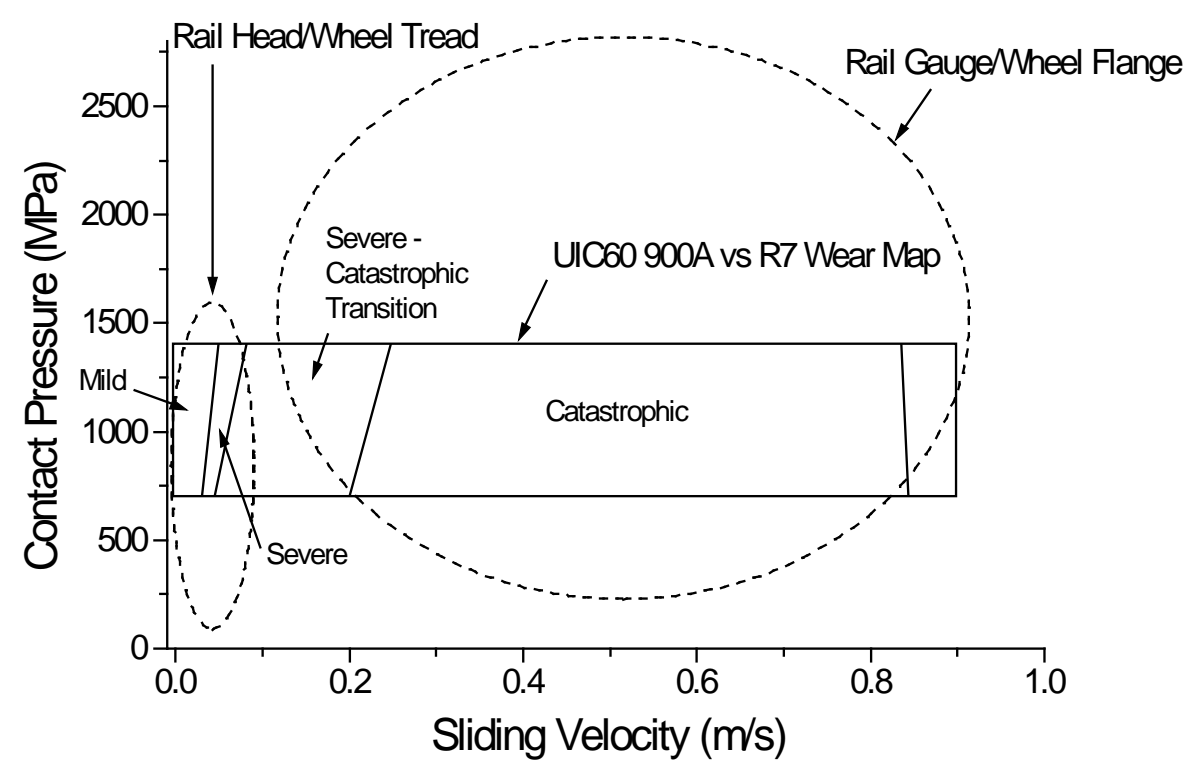

Figure 7. UIC60 900A rail steel wear map (Lewis \& Olofsson [7]).

In the wheel-rail contact both rolling and sliding occur in the contacting zone. Especially in curves, there can be a large sliding component on the contact patch at the track side of the rail head (gauge corner). Due to this sliding, wear occurs in the contact under the poorly lubricated condition that is typical of wheel-rail contact as shown in Figure 2. An observation that can be made on sliding wear is that an increase of the severity of loading (normal load, sliding velocity, or bulk temperature) leads at some stage to a sudden change in the wear rate (volume loss per sliding distance). The severe wear form is often associated with seizure. The transfer from mild acceptable wear to severe/catastrophic wear depends strongly on the surface topography. The loading capability of a sliding contact may be increased considerably by smoothing the surface [8]. Chemically reacted boundary layers imposed by additives in the lubricant can improve the properties of lubricated contacting surfaces and reduce the risk of seizure [9]. Also, as shown by Lewis and Dwyer-Joyce [6], the surface temperature influences the transition from mild to severe wear.

\subsection{Wear measurements and evaluation}

In addition to the contact pressure and the size of the sliding component, natural and applied lubrication strongly influenced the wear rate $[1,10,11]$ for the full-scale test results from the Stockholm test case. Lubricated and non-lubricated as well as seasonal variations were studied. In addition, two different rail hardnesses were studied in the same test curves. Track-side lubrication reduced the wear significantly and a lubrication benefit factor 9 for small radius curves (300 m) was reported. For 600 - $800 \mathrm{~m}$ radius curves the lubrication benefit factor was about 4 . The variation seen in wear rates over the year was probably due to natural lubrication caused by changing weather conditions. An analysis of the relationship between weather conditions and measured rail wear shows that the precipitation has a significant effect on rail wear as shown in Figure 1. Waara [12] reports that gauge face wear in a northern Sweden heavy haul application can be reduced 3-6 times with proper full year lubrication. An on board lubrication system was evaluated by Cantara [13] in a Spanish study. The results were that the flange wear was reduced by a factor 4.5 for wheels equipped with the on board lubrication device.

Despite the obvious effects of applied third body products on wear (and friction) little laboratory data exists defining wear coefficients that can be used, for example, in multi-body dynamics based simulation tools for predicting wheel and rail damage. At the moment dry wear coefficients are used

This paper was published in Vehicle System Dynamics; Special Issue: State of Art Papers of the $23^{\text {rd }}$ IAVSD in 2013. Online version: $\underline{\text { http://dx.doi.org/10.1080/00423114.2013.800215 }}$ 
for all calculations. Friction coefficients can be varied to account for different conditions, but friction in reality is not an "input", it is a result of contact conditions and varies considerably with slip for example. Ideally full creep cures are needed for different third body materials. Recent work by Rovira et al. [14] has shown, however, that the use of dry wear coefficients and not accounting for friction variation with slip can lead to very high errors in resulting contact forces and wear predictions. Work is ongoing to obtain a greater range of wear coefficients [15] and some can be seen in Figure 8 for dry, wet and grease lubricated conditions.

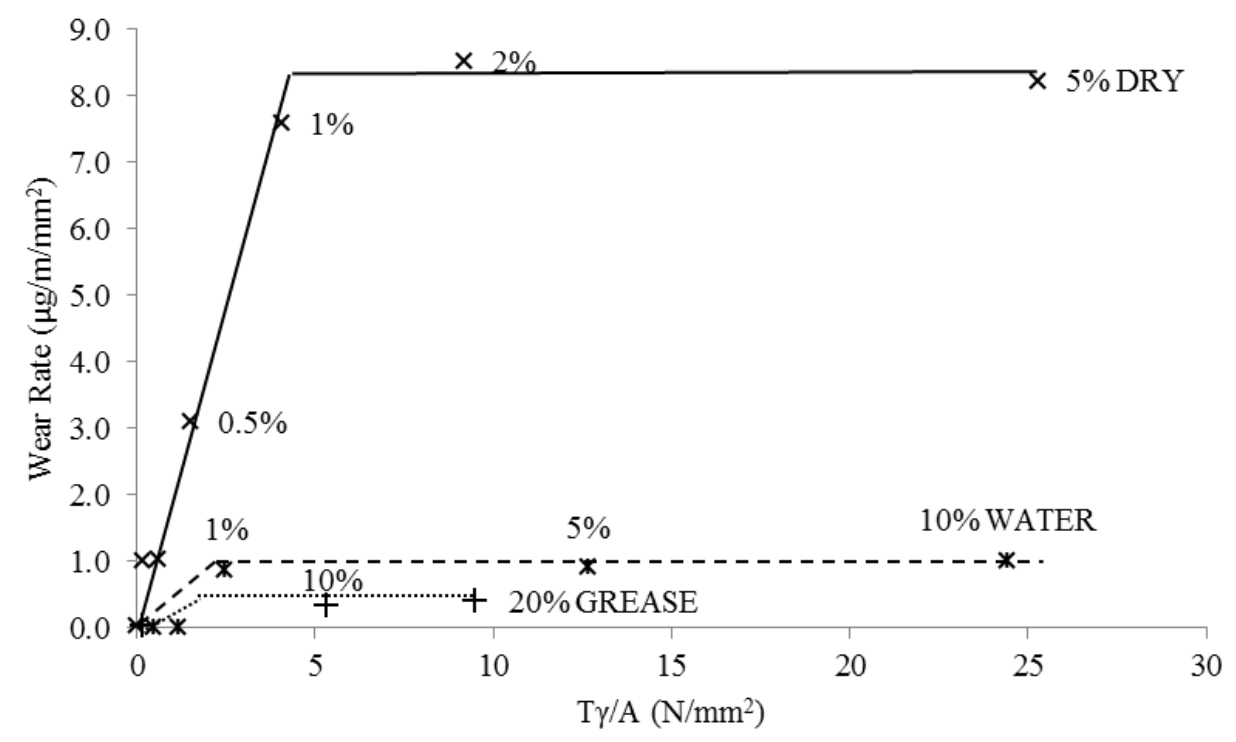

Figure 8. Wear Rates against Tgamma values for dry, wet and grease lubricated conditions [15].

The curve radius of the track has a strong influence on rail wear. The influence depends, also strongly on the vehicles and their behaviour. In the Stockholm test case all vehicles were of the same type and passed over all the test sites with the same frequency. In this case the influence of curve radius can be clearly seen when comparing rail wear rate as function of curve radius. The rail wear rate seems to increase exponentially for decreasing curve radius, as shown in Figure 9.

For a given situation a higher steel grade usually reduces rail wear. This effect is shown in Figure 10 for two different high rails with steel grade UIC 900A respectively UIC 1100 within the same lubricated as well as a parallel non-lubricated $300 \mathrm{~m}$ radius curve. For the non-lubricated curve the ratio between rail wear rate for the 900A grade rail compared to that of the 1100 grade rail is approximately 2. This can be compared with the lubricant benefit factor that was approximately 9 in this curve, as can be seen in Figures 10(i)-10(iv), when comparing the non-lubricated and lubricated cases. The difference between rail head wear (low sliding velocities and contact pressure) and rail gauge wear (high contact pressure and sliding velocities) was seen to be a factor 10 . This is also comparably higher than the rail grade benefit for modern rail steels as UIC 900A and UIC 1100. This observation that the contact conditions in terms of contact pressure and sliding velocity are more important than the grade of steel (900A and 1100) has also been verified in two-roller tests [16]. However, when Lewis and Olofsson [7] compared rail steel wear coefficients taken from laboratory tests run on twin disc and pin-on-disc machines as well as those derived from measurements taken in the field, they found that the introduction of more modern rail materials had reduced wear rates by up to an order of magnitude in the last 20 years. 


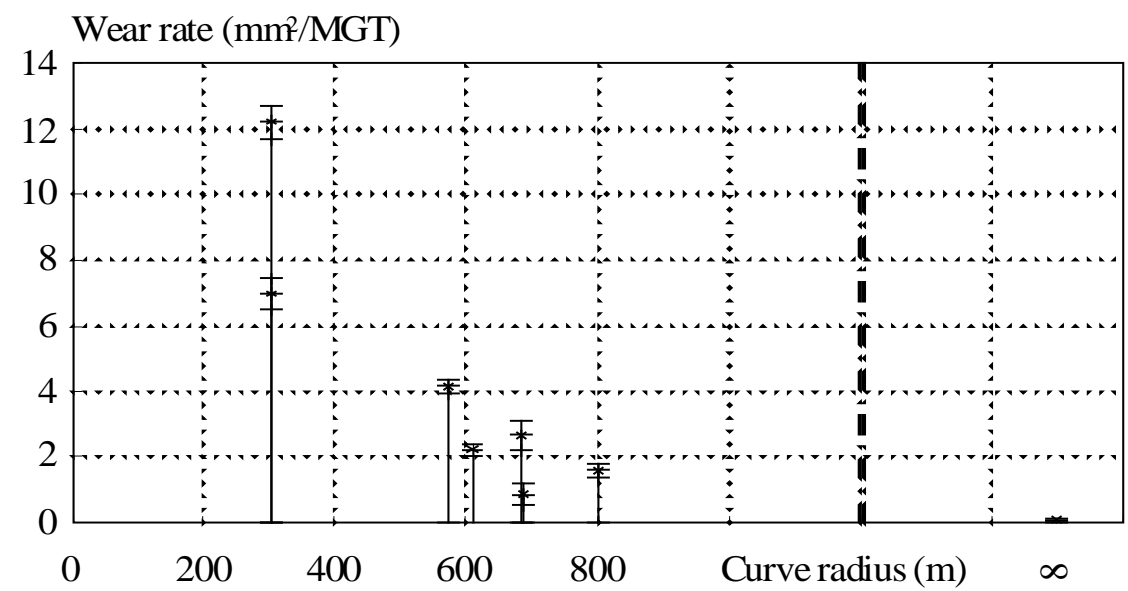

Figure 9. Wear rate for high rail as function of curve radius in the Stockholm test case (from Nilsson [1]). MGT = mega gross tonne traffic.
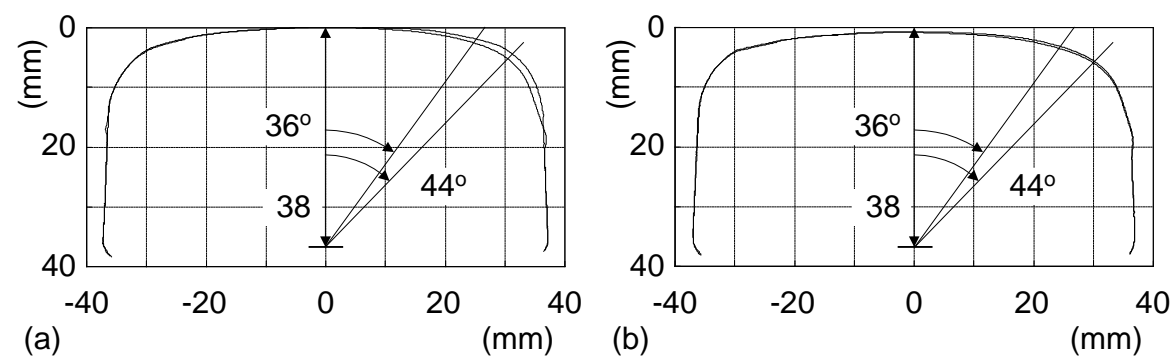

(i). Results from form measurements of high rail at test start and after 2 years of traffic: (a) new rail at test start, (b) worn rail at test start. The curve radius is $346 \mathrm{~m}$, the rail steel grade is UIC 900A and the curve was lubricated during the measuring period.

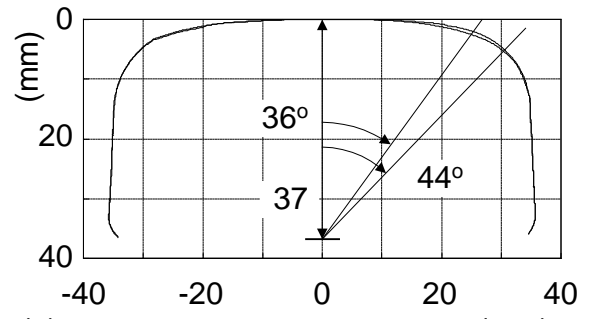

(a)

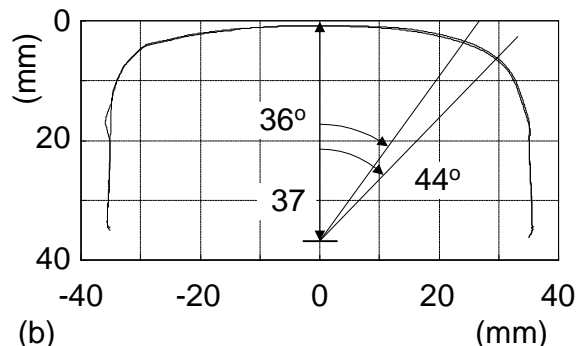

(b)

$(\mathrm{mm})$

(ii). Results from form measurements of high rail at test start and after 2 years of traffic: (a) new rail at test start, (b) worn rail at test start. The curve radius is $346 \mathrm{~m}$, the rail steel grade is UIC 1100 and the curve was lubricated during the measuring period.
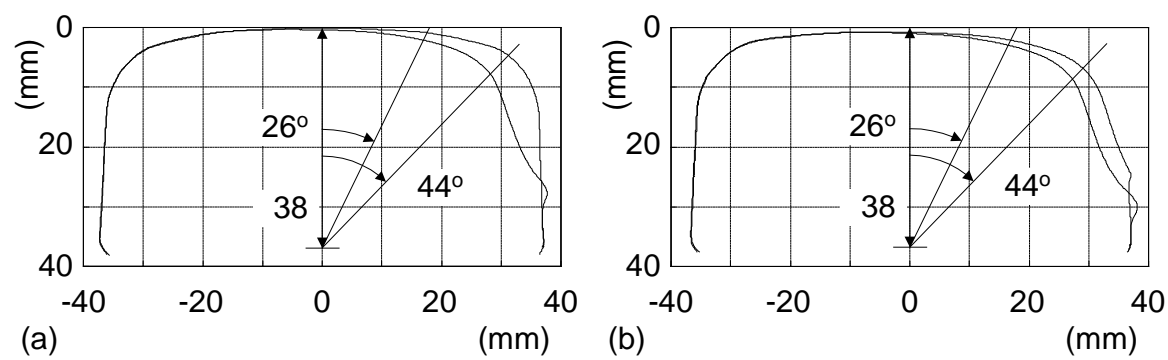

(iii). Results from form measurements of high rail at test start and after 2 years of traffic: (a) new rail at test start, (b) worn rail at test start. The curve radius is $303 \mathrm{~m}$, the rail steel grade is UIC 900A and the curve was not lubricated during the measuring period. 

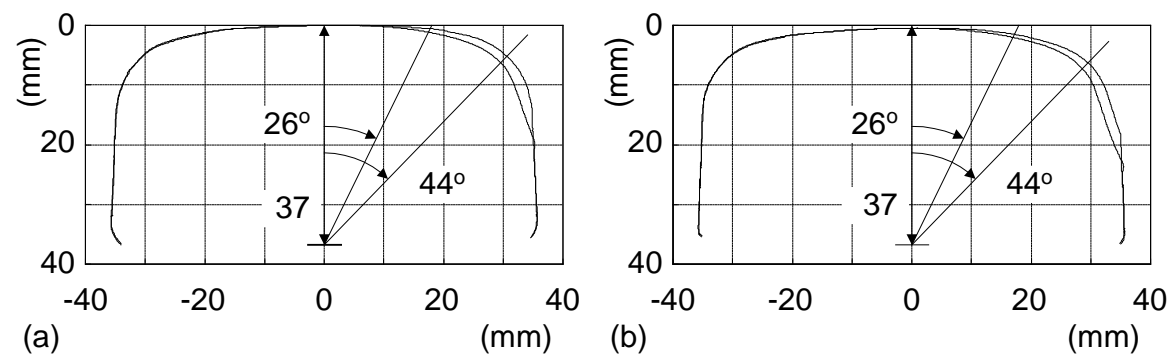

(iv). Results from form measurements of high rail at test start and after 2 years of traffic: (a) new rail at test start, (b) worn rail at test start. The curve radius is $303 \mathrm{~m}$, the rail steel grade is UIC 1100 and the curve was not lubricated during the measuring period.

Figure 10. Wear of UIC 900A and 110 rail in lubricated and unlubricated curves (from [1])

Fully pearlitic rail steels are still the most common and are used by most railways. Pearlitic is a lamellar product of eutectoid composition that is formed in steel during transformation under isothermal continuous cooling. It consists of ferrite and cementite. Perez-Uzeta and Beynon [17] have shown that wear rate of pearlitic rail steel decreases with lower interlamellar spacing between the cementite lamella giving a corresponding increase in hardness. Steels with a bainitic microstructure are the other main rail steels. They have shown better rolling contact fatigue resistance than pearlitic rail steels. However, the wear resistance of bainitic rail steels is inferior to that of pearlitic rail steels at a fixed tensile strength, as shown by Garnham and Beynon [18] and Mitao et al. [19].

\section{Particle emission}

The London Underground, the world's first sub-terrain metro system, opened in 1863 and the first report of airborne wear particles in rail transport was published in 1909 (Abbasi et al.[20]). As pointed out by Olander and Jansson [21] the high mass concentration levels of wear particles in railway tunnels and underground stations have raised worries among researchers concerned with air quality. They also emphasized the need for emission mitigation measures.

It can be noted that the exhaust emissions of particulate matter (PM) from the rail transport sector are less than those from the road transport, aviation, and shipping sectors (Uherek et al., [22]; Fuglestvedt et al., [23]). Although no publications on the relative contributions from rail traffic to non-exhaust emissions are known to the authors. It can be predicted that this contribution will be increased and increase worries as on one hand current exhaust emission directives such as Euro V and Euro VI and Tiers 2 and 4 impose emission limits that are progressively tightening over the years, gradually reducing total PM emitted by engines on the other hand there is also a general trend towards higher ground transportation speeds and increasing frequency of rail transport, which most likely cause higher wear and consequently more emitted wear particles (Abbasi et al. [24]). The non-exhaust sources from rail traffic can be classified as airborne wear particles from the wheel-rail contact, but also wear particles from braking materials as well as from the interaction from the overhead line and the contact strip contributes. In addition, re-suspension from a running train may contribute to this effect. In both the US and EU, legislation has determined limitations for the amount of $\mathrm{PM}_{10}$ and $\mathrm{PM}_{2.5}$. Note that $\mathrm{PM}_{10}$ refers to particles with an aerodynamic diameter less than $10 \mu \mathrm{m}$ and $\mathrm{PM}_{2.5}$ refers to particles with and aerodynamic diameter less than $2.5 \mu \mathrm{m}$. and certain metal compounds for outdoor air quality. Table 1 presents a comparison of European and US legislation for particulate matter

Table 1. A comparison of European (EU Directive 2008/50/EC, 2008 [25]) and US (EPA NAAQS, 2012 [26]) legislation for outdoor air quality in terms of particulate matter.

This paper was published in Vehicle System Dynamics; Special Issue: State of Art Papers of the $23^{\text {rd }}$ IAVSD in 2013. Online version: http://dx.doi.org/10.1080/00423114.2013.800215 


\begin{tabular}{|l|c|c|}
\hline & $\mathrm{PM}_{2.5}\left(\mu \mathrm{g} \mathrm{m}^{-3}\right)$ & $\mathrm{PM}_{10}\left(\mu \mathrm{g} \mathrm{m}^{-3}\right)$ \\
\hline US Daily 24h & 35 & 150 \\
\hline US Annual & 12 & - \\
\hline EU Daily 24 h & - & 40 \\
\hline EU Annual & 25 & 40 \\
\hline
\end{tabular}

${ }^{\mathrm{a}}: 50 \mu \mathrm{g} / \mathrm{m}^{3}$ must not be exceeded 35 times in a calendar year

Much work has been put into clarifying the different operating conditions in the two basic types of contacts in wheel-rail contact. Lewis and Olofsson [7] representation of the operating conditions for a wheel tread-rail head contact and a wheel-flange-rail gauge contact is shown in Figure 7. These operating conditions can be briefly described as the contact pressure and the sliding velocity significantly increasing when going from straight track to curving. For extreme cases such as for the leading wheel pair in a narrow curve, heavy acceleration, or heavy braking the sliding velocity can increase to even higher levels than presented in Figure 7.

\subsection{Particle measurements from laboratory experiments}

The experimental work in the study (Sundh and Olofsson [27]) is based on the sliding part of a wheelrail contact simulated with pin-on disc methodology using a clean room technique (Olofsson, Jansson and Olander [28]) to monitor airborne particle emissions from the pin on disc contact. Sliding velocities at or lower than $0.1 \mathrm{~m} \mathrm{~s}^{-1}$ has been considered to represent rail head wheel tread contacts and sliding velocities well above $0.1 \mathrm{~m} \mathrm{~s}^{-1}$ represents wheel flange-rail gauge contacts or heavy breaking actions.

Airborne particle measurements performed with Ptrak and Grimm instruments for a pin-on-disc tests [27] (with sliding velocities of $0.1,4$, and $8 \mathrm{~m} \mathrm{~s}^{-1}$ ) were conducted as part of this study. The results show a significant difference in the number concentration of the airborne particles for the first part of the test run, see Figure 11. The test runs presented in Figure 11 were conducted with both high and low sliding velocities at a high nominal contact pressure. The two lower graphs of Figure 11 represent severe cases either for a wheel flange/ gauge corner contact or heavy acceleration or braking. The main difference between the two particle measuring instruments used is the size range of the measured particles where the Ptrak measurements include smaller particles than the Grimm instrument. As follows when the number of particles measured with a diameter of less than $1 \mu \mathrm{m}$ which is presented in Figure 11 the difference in concentration between the two are represented by particles in the size interval 0.02 to $0.25 \mu \mathrm{m}$. It can be seen that the concentration of particles increases as the sliding velocity is increased with both of the instruments. For the two cases with high sliding velocities it can be seen that during the running in process the large number concentration difference between the two instruments corresponds to high levels of particles up to $0.25 \mu \mathrm{m}$ in diameter. When studying the airborne particles collected on filters with SEM imaging it is possible to see particles of sizes ranging from less than $20 \mathrm{~nm}$ to particles larger than $10 \mu \mathrm{m}$. When focusing on particles collected for a lower sliding velocity, where the bulk temperature of the samples only experienced a small increase, it is possible to see larger chunks of material worn off by identification of their morphology an abrasive wear mechanism, see Figure 12. Elevated temperatures were registered as the sliding velocity increased, and particles consisting of a heap of small agglomerated particles could be found, as shown in Figure 13. Signs of more adhesive wear mechanisms could also be seen when identifying thin

This paper was published in Vehicle System Dynamics; Special Issue: State of Art Papers of the $23^{\text {rd }}$ IAVSD in 2013. Online version: http://dx.doi.org/10.1080/00423114.2013.800215 
particles which looked like a crackled slice of metal, see Figure 14. According to the INCA energy mapping it consisted of the combination of the elements Fe, $\mathrm{O}$ and $\mathrm{Mn}$.

The size and shape of the small particles in the ultra-fine region are of interest when discussing contact temperatures. An example of such a particle is illustrated in Figure 15 - observe the almost round shape. These particles can be found in a higher concentration when the sliding velocity of the test run was increased.
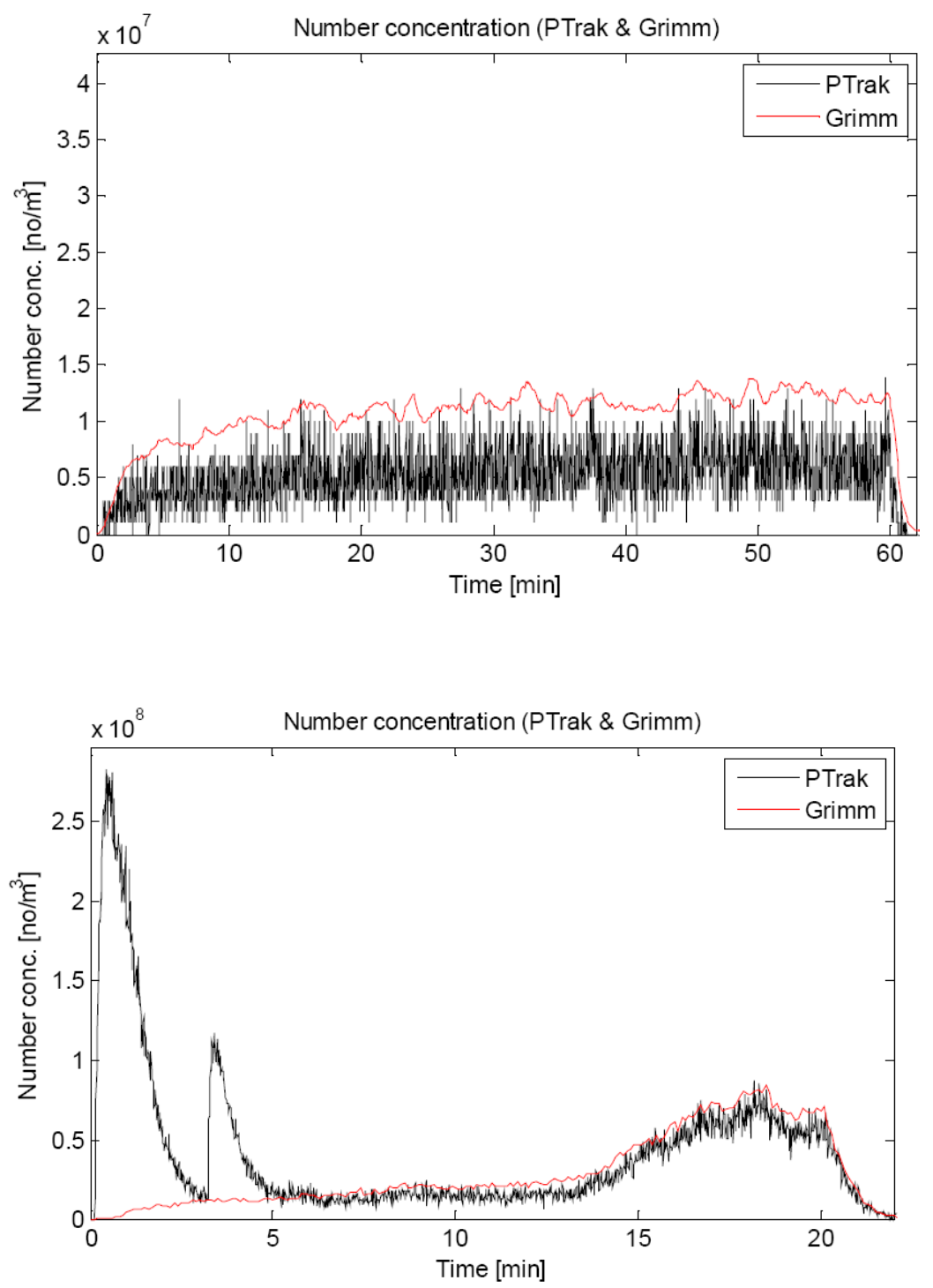


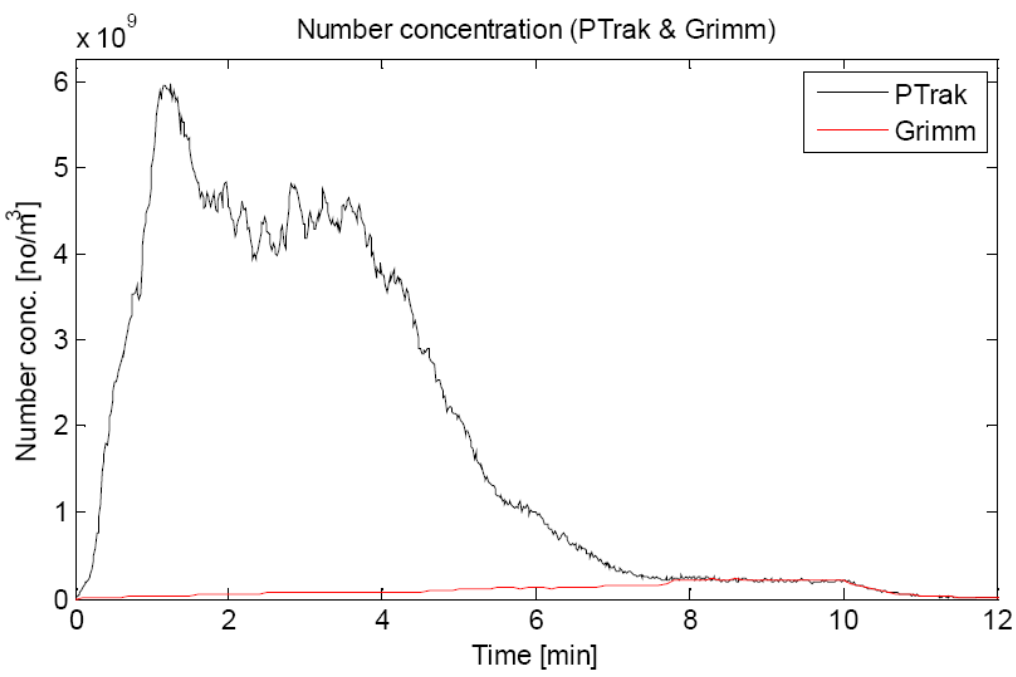

Figure 11. The number concentration of airborne particles from the Ptrak in the particle size interval $(0.02-1 \mu \mathrm{m})$ and the Grimm instrument for the particle size interval $(0.25-1 \mu \mathrm{m})$. The test runs presented are performed at sliding velocities of $0.1,4$, and $8 \mathrm{~m} \mathrm{~s}^{-1}$ [27]

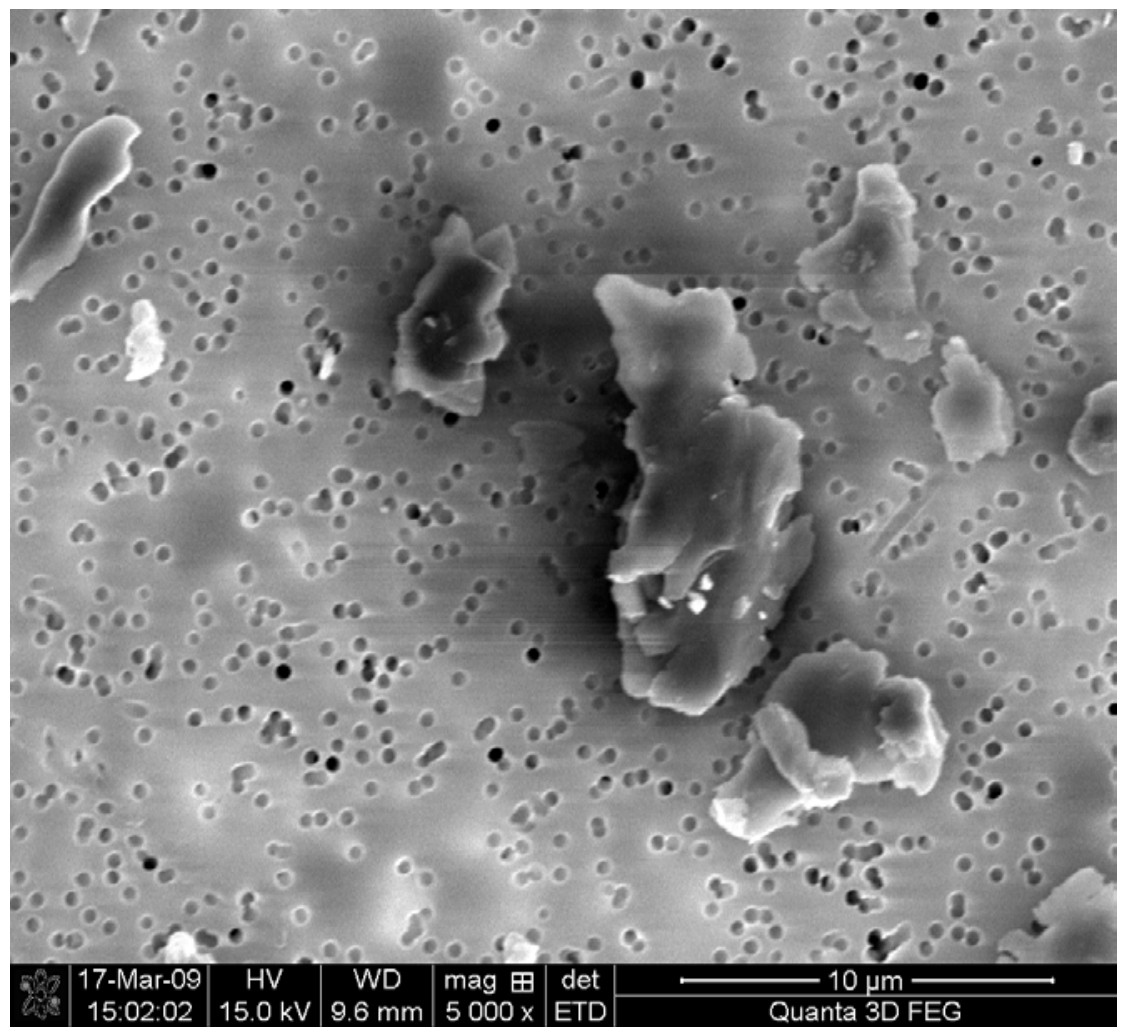

Figure 12. Large particles collected from a test run performed at $0.1 \mathrm{~m} \mathrm{~s}^{-1}$ [27]. 


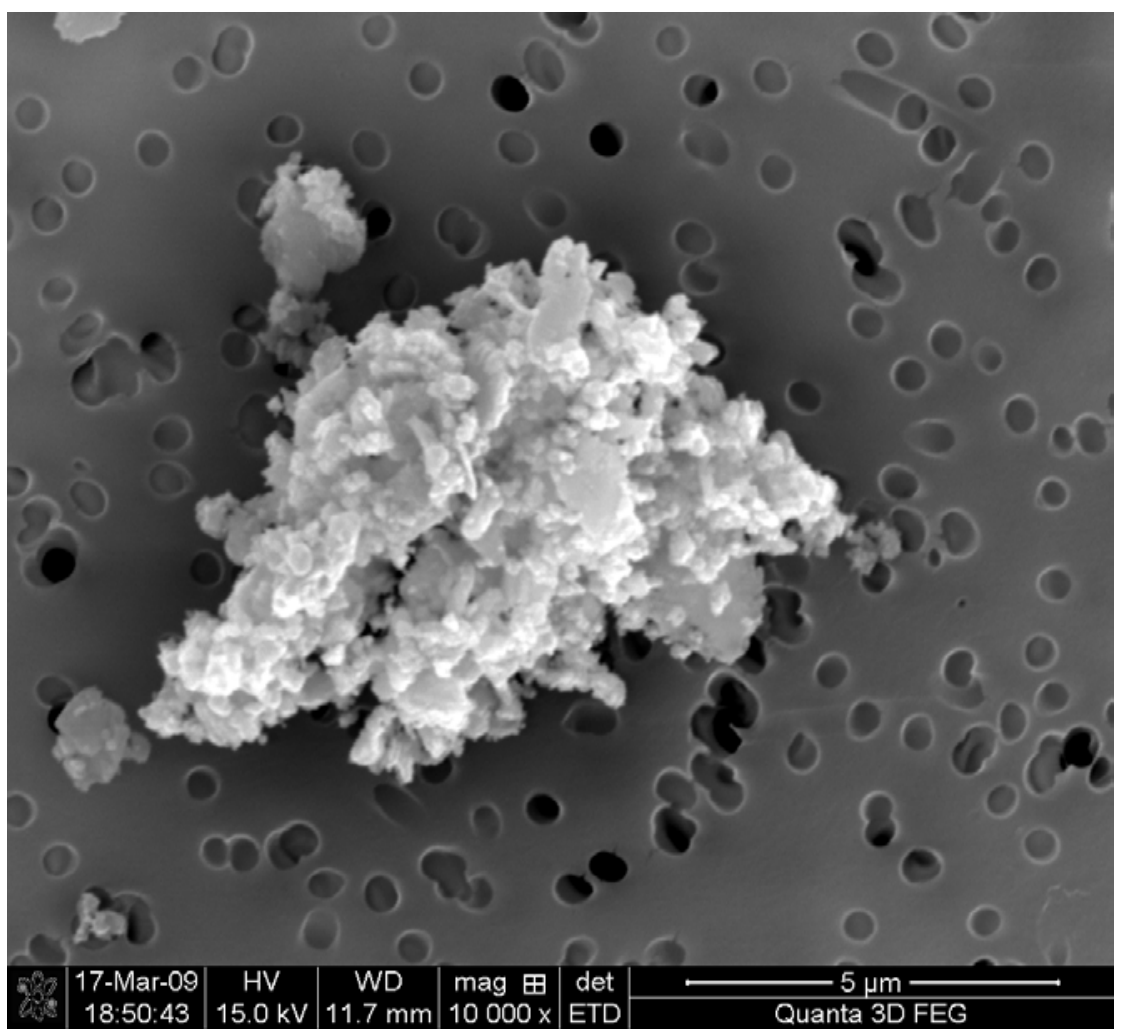

Figure 13: A large particle seeming to consist of small agglomerated particles. The sliding velocity of the test run was $0.8 \mathrm{~m} \mathrm{~s}^{-1}[26]$.

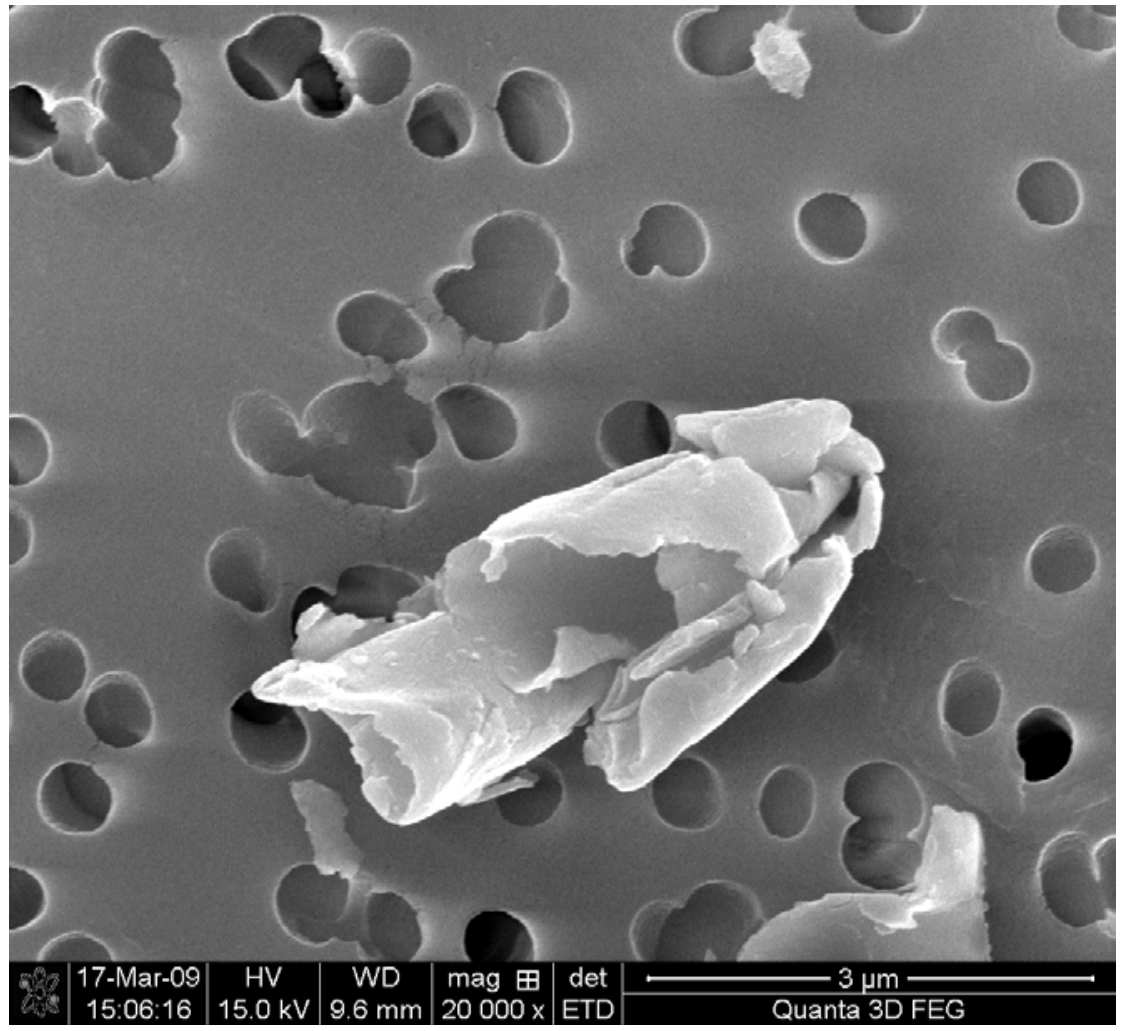

Figure 14. A thin wear particle consisting of significant levels of $\mathrm{Fe}, \mathrm{O}$ and $\mathrm{Mn}$. The sliding velocity of the test run was $0.8 \mathrm{~m} \mathrm{~s}^{-1}$ [27].

This paper was published in Vehicle System Dynamics; Special Issue: State of Art Papers of the $23^{\text {rd }}$ IAVSD in 2013. Online version: http://dx.doi.org/10.1080/00423114.2013.800215 


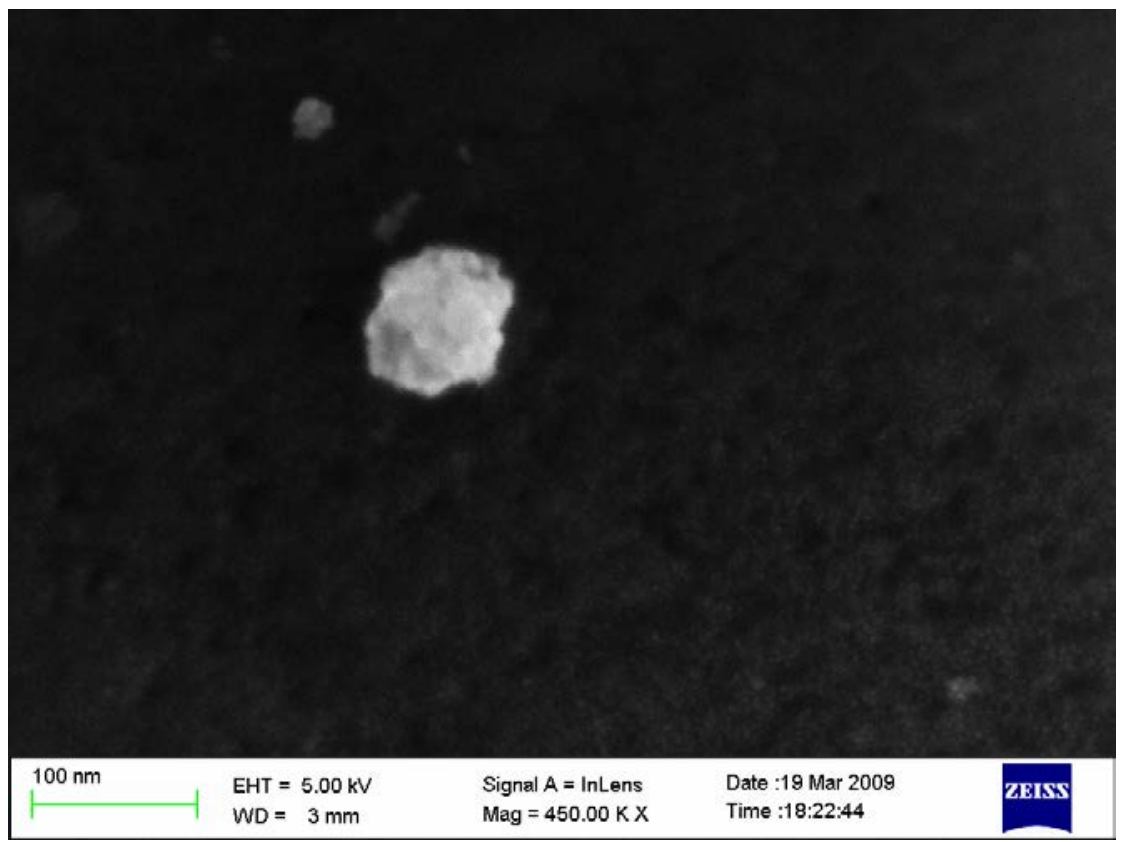

Figure 15: One of the small particles in the ultra-fine size interval found on a filter from a test with a sliding velocity of $0.8 \mathrm{~m} \mathrm{~s}^{-1}$ [27].

Abbasi et al [29] investigated friction modifiers' effects on airborne particles characteristics generated in wheel-rail contacts in laboratory conditions. The same test set up as Sundh and Olofsson [27] was used with the addition of an aerosol instrument that could measure particles down to $10 \mathrm{~nm}$ (SMPS). Airborne particle characteristics were investigated in dry contacts and in ones lubricated with biodegradable rail grease as well as water- and oil-based friction modifiers. The number of particles declined with the grease; the number of ultrafine particles increased with the water-based friction modifier, mainly due to water vaporization. Figures 16 to 19 show that even the low-speed sliding contact $\left(0.1 \mathrm{~m} \mathrm{~s}^{-1}\right)$ between wheel and rail leads to wear. This wear process subsequently generates coarse, fine, and ultrafine airborne particles regardless of the specific contact conditions, though the numbers of generated particles are highly dependent on the type of lubricant in the contact. The number of coarse particles was effectively reduced when rail grease or friction modifiers were used. The greatest effectiveness was recorded when biodegradable rail grease was used, resulting in a 95\% reduction in the coarse particle concentration. Friction modifiers also reduced the particle concentration, by approximately $70 \%$ for oil-based and 30\% for water-based friction modifiers.

This effective reduction in the number of coarse particles can be explained by a shift from dry contact to boundary lubrication conditions. Boundary lubrication reduces the adhesive force between two surfaces in contact and can reduce wear. In addition, some particles could be trapped in the lubricant and not released to the ambient air.

The number of ultrafine particles decreased when biodegradable rail grease or oil-based friction modifier was used. In contrast, the concentration of ultrafine particles increased drastically when water-based lubricant was used. This effect can be explained by frictional heat in the wheel-rail contact.

This paper was published in Vehicle System Dynamics; Special Issue: State of Art Papers of the $23^{\text {rd }}$ IAVSD in 2013. Online version: http://dx.doi.org/10.1080/00423114.2013.800215 


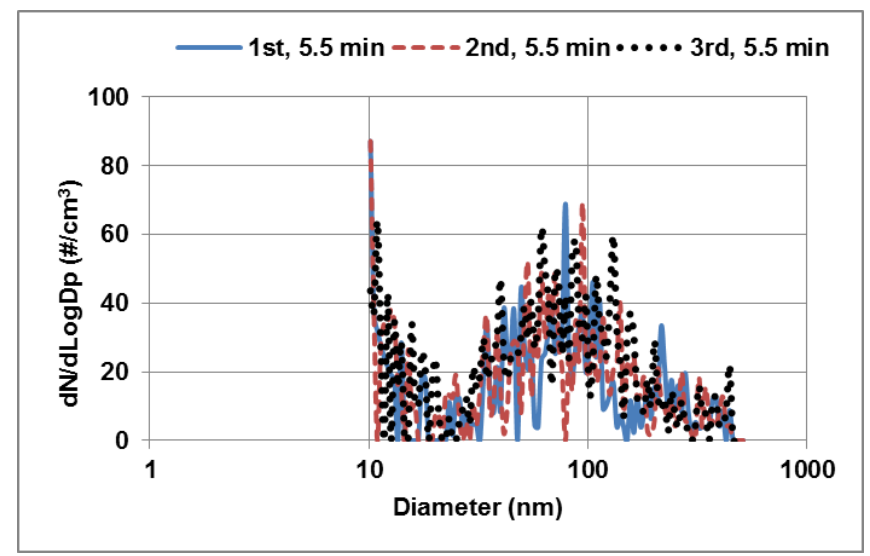

Figure 16. Typical particle measurement for a dry wheel-rail contact: the load applied on the roundhead pin is $40 \mathrm{~N}$ and the sliding velocity is $0.1 \mathrm{~m} \mathrm{~s}^{-1}$. These data represent the size distribution of particles in the $10<\mathrm{dp}<540 \mathrm{~nm}$ interval recorded using an SMPS. [29]

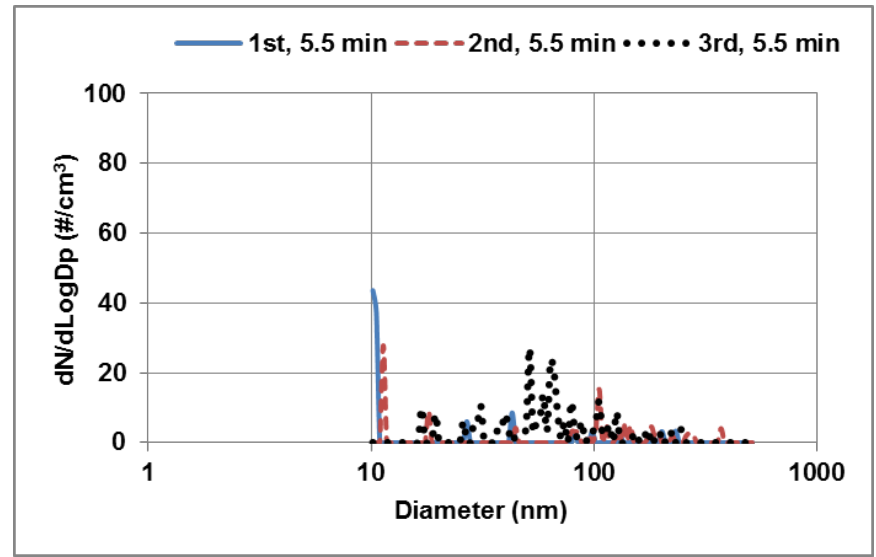

Figure 17. Typical particle measurement for a lubricated wheel-rail contact (friction modifier type A): the load applied on the round-head pin is $40 \mathrm{~N}$ and the sliding velocity is $0.1 \mathrm{~m} \mathrm{~s}^{-1}$. These data represent the size distribution of particles in the $10<\mathrm{dp}<540 \mathrm{~nm}$ interval recorded using an SMPS [29].

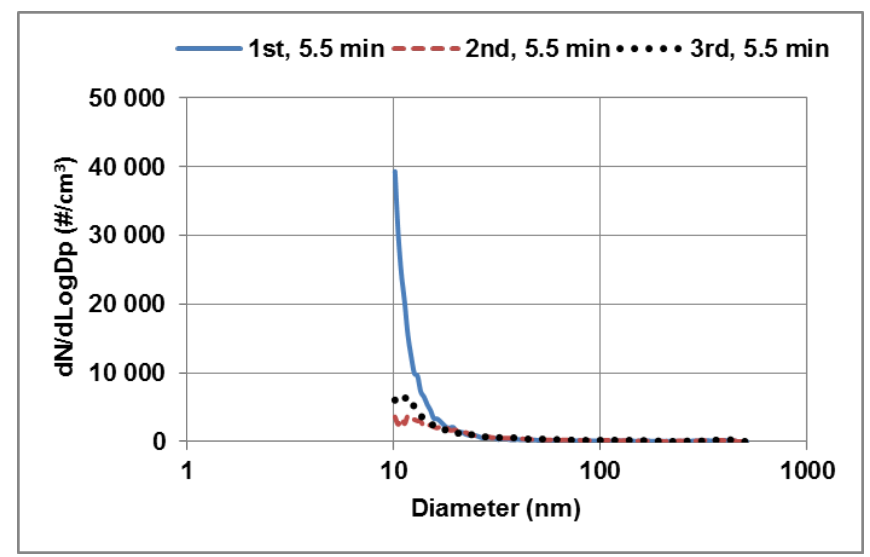

Figure 18. Typical particle measurement for a lubricated wheel-rail contact (friction modifier type B): the load applied on the round-head pin is $40 \mathrm{~N}$ and the sliding velocity is $0.1 \mathrm{~m} \mathrm{~s}^{-1}$. These data represent the size distribution of particles in the $10<\mathrm{dp}<540 \mathrm{~nm}$ interval recorded using an SMPS [29]. 


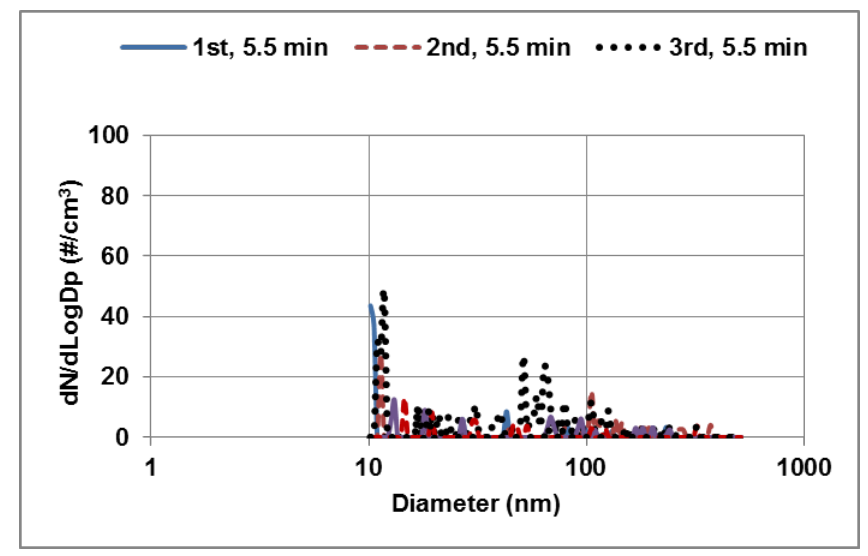

Figure 19. Typical particle measurement for a lubricated wheel-rail contact (biodegradable rail grease): the load applied on the round-head pin is $40 \mathrm{~N}$ and the sliding velocity is $0.1 \mathrm{~m} \mathrm{~s}^{-1}$. These data represent the size distribution of particles in the $10<\mathrm{dp}<540 \mathrm{~nm}$ diameter interval recorded using an SMPS [29].

\subsection{On-board particle measurements}

There are few measurement performed on-board running trains with the exceptions of Fridell et al. [30] and Abbasi et al [31]. Fridell et al. [30], reported particle characteristics and emission factors for wear particles from a running Regina train. They investigated particles size in 7 intervals and aimed to investigate 27 elements among the collected particles. The curve negotiation effects were not traceable in their work as they used one sampling point that was located between the two coaches.

They instrumented the train with measurement points both in the middle of the train between the bogies and also at one side near a disc brake. A series of tests were performed using a Regina 250' (Bombardier Regina) train [31]. Four tests runs were conducted under normal traffic conditions on this regular Swedish inter-city tracks over the course of 3 days. The maximum allowable operational speed of the train was $200 \mathrm{~km} \mathrm{~h}^{-1}$ when both mechanical and electrical brakes were active (the speed was reduced to $180 \mathrm{~km} \mathrm{~h}^{-1}$ when the electrical brake was intentionally deactivated). The train followed the normal traffic operation when it was on main tracks. Parts of the test runs were conducted on a lowtrafficked track, where the maximum operational speed was only $90 \mathrm{~km} \mathrm{~h}^{-1}$. That area was green and less influenced by other man-made particles. It was fairly isolated from disturbances and artifacts; therefore, most data related to mechanical braking were gathered from this part of the test route. Inhalable airborne particles have documented health effects.

Two airborne particle sampling points were designated, one near a pad-rotor disc brake contact and a second, global sampling point under the frame, not near a mechanical brake or the wheel-rail contact. The total numbers and size distributions of the particles detected at these two sampling points were registered and evaluated under various conditions (e.g. activating/deactivating the electrical brake or negotiating curves).

During braking, three speed/temperature-dependent particle peaks were identified in the fine region, representing particles $280 \mathrm{~nm}, 350 \mathrm{~nm}$, and $600 \mathrm{~nm}$ in diameter. In the coarse region, a peak was discerned for particles 3-6 $\mu \mathrm{m}$ in diameter. Effects of brake pad temperature on particle size distribution were also investigated. Results indicate that the $280 \mathrm{~nm}$ peak increased with increasing temperature, and that using electrical braking significantly reduced airborne particle numbers. Analysis on filters capturing airborne particles using FESEM images captured particles sizing down to $50 \mathrm{~nm}$. Analysis with ICP-MS indicated that $\mathrm{Fe}, \mathrm{Cu}, \mathrm{Zn}, \mathrm{Al}, \mathrm{Ca}$, and $\mathrm{Mg}$ were the main elements constituting the particles.

This paper was published in Vehicle System Dynamics; Special Issue: State of Art Papers of the $23^{\text {rd }}$ IAVSD in 2013. Online version: http://dx.doi.org/10.1080/00423114.2013.800215 


\section{Adhesion}

\subsection{Adhesion, traction and friction}

From a strict tribological point of view adhesion is the force that is required to separate two surfaces which have been brought into contact and is a term usually used to describe how well surface coatings or paint are bonded to the surfaces which they coat [32, 33]. However, the word adhesion has become widely used among the wheel-rail research community to describe the tangential force resulting at the wheel-rail contact as used in [34, 35]. Friction force is defined as the resistance encountered by one body moving over another body [36].

a)

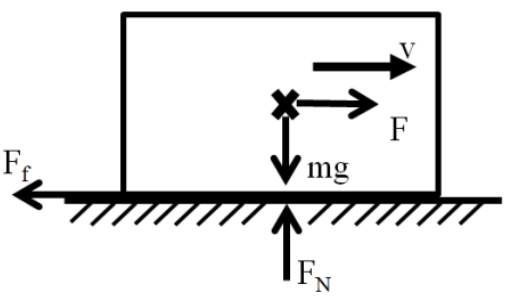

b)

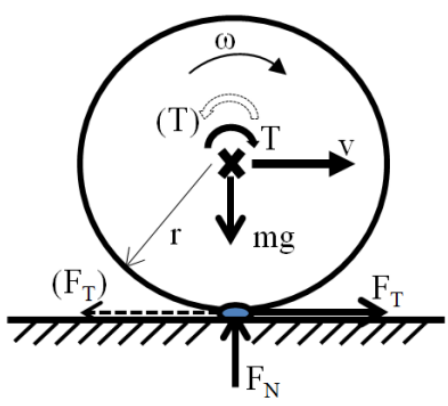

Figure 20. Schematic view of a) pure sliding contact b) rolling/sliding contact under acceleration. Where $F_{N}$ is the resulting normal force; $v$ is the forward speed; $r$ is the wheel radius; $\omega$ is the rotational speed of the wheel; $\mathrm{T}$ is the applied torque of a driving wheel; $\mathrm{F}_{\mathrm{N}}$ is the resulting tangential force. ( $\mathrm{T}$ ) and $\left(\mathrm{F}_{\mathrm{N}}\right)$ is the torque and force of a braking wheel.

The difference between friction and adhesion can be illustrated with the help of Figure 20. Figure 20 (a) shows a block sliding at velocity, $v$ along a stationary plane surface. The block is subject to a normal force, $F_{N}$ (due to the weight of the block) and a horizontal force, $F$. The horizontal force which opposes the motion of the block is deemed the friction force, $F_{f}$. The static friction force is equal to the horizontal force required to initiate sliding while the kinetic friction force is equal to the horizontal force required to maintain sliding [36]. Generally the static friction is higher than the kinetic friction. The ratio between the friction force and the normal force is referred to as the friction coefficient (Equation 1). Figure 20 (a) presents a case of pure sliding and the friction force is dependent on: interaction and deformation of microscopic asperities in the contact and adhesion forces between the two sliding surfaces [34].

$$
\mu_{f}=\frac{F_{f}}{F_{N}}
$$


Ever since the invention of the wheel it has been known that it is far more efficient to move heavy objects on wheels or rollers rather than sliding them over solid surfaces. Typically for a steel cylinder rolling on a steel surface, the coefficient of rolling resistance (free rolling) is of the order of 0.001 [37]. For most metal pairs in sliding contact the friction coefficient is in the order of $0.3-1.0$ [38]. The coefficient of rolling resistance for any rolling contact is inversely proportional to the contact modulus. For example the coefficient of rolling resistance for a pneumatic tyre on asphalt is typically 0.01. Driving locomotive wheels however, are not pushed along the track but have a torque applied about their center of rotation. Figure 20 (b) shows a cylinder rolling along a stationary plane surface. This is analogous to the case of a wheel rolling along a rail. The wheel is subject to normal force, $F_{N}$ and travels along the rail at velocity, $v$. The wheel is subject to torque, $T$ which maintains the angular velocity of the wheel, $\omega$ and also causes a reactive tangential force, $F_{T}$, at the wheel-rail interface. The tangential force of a driving wheel is known as traction which ultimately propels the wheel along the rail. During deceleration, the tangential force opposes the running direction indicated as $F_{T}$ in brackets in Figure 20 (b). The tangential force in accelerating or decelerating cases is named adhesion. The ratio between the adhesion force and the normal force is known as the adhesion coefficient (Equation 2) [39].

$\mu_{a}=\frac{F_{T}}{F_{N}}$

During acceleration or when maintaining a constant speed due to the inertia of the wheel and vehicle, the tangential velocity at the wheel surface, $\omega r$, for a driven wheel will always be greater than its body velocity, $v$. The difference between the tangential velocity of the wheel, $\omega r$, and the body velocity, $v$, is referred to as creep or creepage and is usually given as a percentage (Equation 2) [39].

$$
\xi=\frac{v-\omega r}{\frac{1}{2}(v+\omega r)}
$$

Since adhesion refers to the tangential force in the longitudinal direction, the creep discussed in this section is limited to longitudinal creep. Sometimes the wheel's body velocity, $v$, is also used as the denominator of Equation (3) in railway dynamics assuming small creep. In the railway text, slip is sometimes used instead of creep. But in order to distinguish from micro slip/stick, the term creep will be used throughout instead of slip.

Figure 21 shows the relationship between creep and adhesion for a typical dry wheel-rail contact. This plot of adhesion against creep is known as a creep curve. Note that this plot can also be called traction versus slip curve. As the tractive force at the wheel is increased so too is the amount of creep in an approximately linear fashion. This linear region of the curve ends as the adhesion reaches its saturation value at typically $1-2 \%$. At this point the adhesion equals the friction force of two bodies identical to the wheel and rail in pure sliding under identical contact conditions. Figure 21 also shows that the contact patch between the wheel and rail is divided into stick and slip regions. Longitudinal creep and tangential forces arise due to the slip that occurs in the trailing region of the contact patch [40]. With increasing tangential force, the slip region increases and the stick region decreases, resulting in a rolling and sliding contact. When the tangential force reaches its saturation value, the stick region disappears, and the entire contact is in a state of pure sliding. The maximum level of tangential force depends on the capacity of the contact patch to absorb the adhesion which is expressed in the form of the coefficient of friction [36]. Since part of the friction is utilised by lateral phenomenon and also due to the axle load redistribution, the maximum adhesion or the limiting friction in the longitudinal direction shown in Figure 21 is less than total friction [41].

This paper was published in Vehicle System Dynamics; Special Issue: State of Art Papers of the $23^{\text {rd }}$ IAVSD in 2013. Online version: http://dx.doi.org/10.1080/00423114.2013.800215 


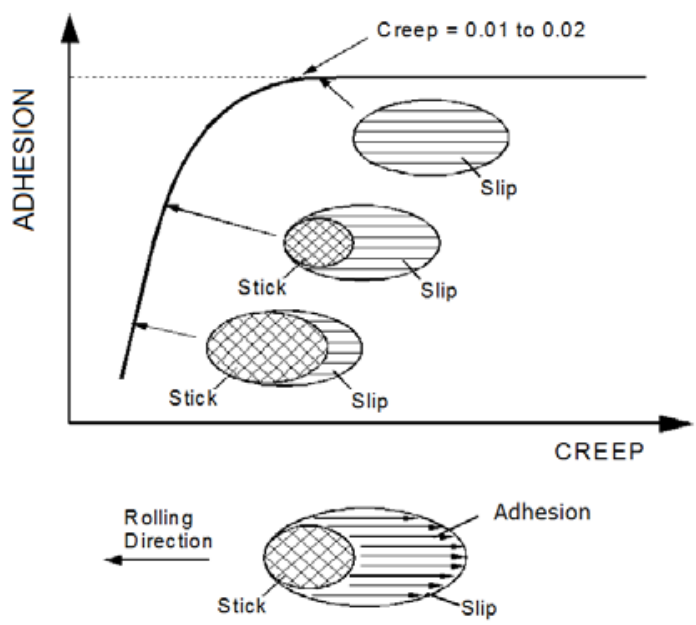

Figure 21. Creep curve showing the relationship between the adhesion and creep [36]

Figure 22 shows creep curves generated using a twin-disc tester [42] which simulates the rolling/sliding contact between the wheel and rail. The curves have been generated with different contaminants in the disc contact. As you can see the effect of the different contaminants is to lower the underlying friction and hence reduce the traction at which saturation occurs altering the form of the creep curve.

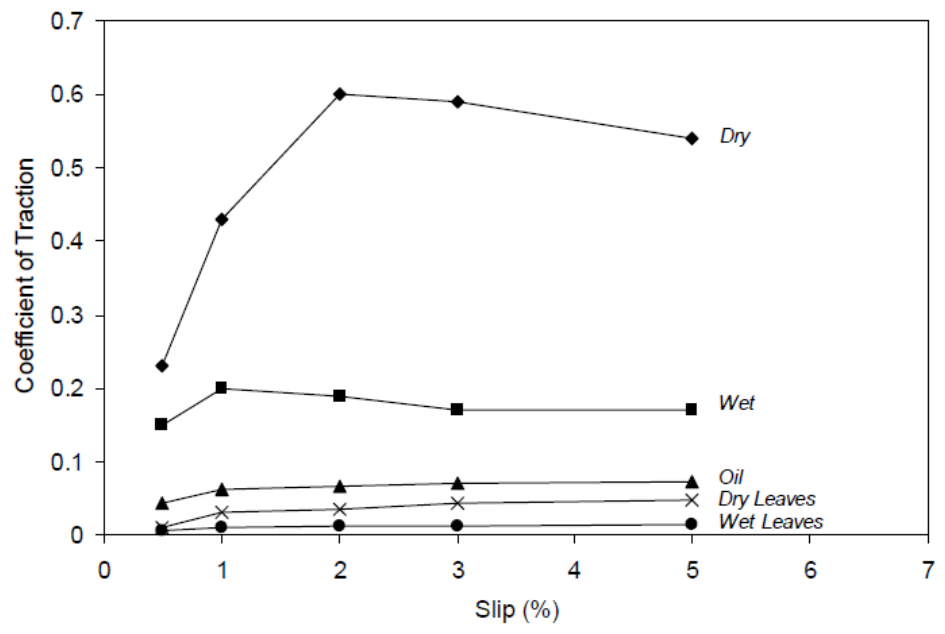

Figure 22. Creep curves generated by twin-disc testing [42]

The coefficient of friction is a system property rather than a material property. It does not only depend on the mating materials but also on factors, such as temperature and humidity. The theory of friction is comprehensively discussed in Hutching [43]. The adhesion between the wheel and rail cannot be measured directly although friction can be measured on the rail surface. Measuring techniques include a hand-pushed tribometer and a vehicle companion Tribo-Railer [44]. Both of them use small steel wheels rolling on the rail. The wheel is connected to a clutch which is gradually engaged. At a certain point the torque on the wheel will overcome the friction between the wheel and rail causing the wheel to slip. A new device called the pendulum rig [45] has also been recently investigated. Based on an energy loss principle, such as used in the Charpy impact test, the device is able to measure friction on a very short section $(12.7 \mathrm{~cm})$ of a rail which makes it suitable for investigating areas of adhesion loss on the rail which are often very localised. It must be noted however, that this measurement of friction is the friction between the device being used and the rail not the actual wheel and rail and hence can only be used as an indication as to the maximum adhesion available. Moreover, the results of the

This paper was published in Vehicle System Dynamics; Special Issue: State of Art Papers of the $23^{\text {rd }}$ IAVSD in 2013. Online version: http://dx.doi.org/10.1080/00423114.2013.800215 
measurement techniques may differ slightly even when measured under similar conditions. For example, a hand-push tribometer and a Tribo-Railer give different friction coefficient values when both measured on the dry railhead [44] because of the difference in measuring speed, length and measuring wheel. In the laboratory a pin-on-disc rig is often used to measure the friction coefficient based on a stationary loaded pin sliding on a rotating disc. The results of friction coefficient are also different depending on the sliding speed, applied load, etc.

\subsection{Wheel-rail adhesion under contaminated conditions}

In both railway operation and maintenance, wheel-rail adhesion plays an important role. If it is too low, the vehicle has less traction leading to a reduction of braking force causing safety issues and leading to timetable disruption. If it is too high, the wheel and rail is subject to excessive shear stress leading to higher wheel and rail wear [36]. The requirements of the adhesion coefficient can be divided into three categories: for driving or braking the rolling stock at a given full capacity, to keep the timetable and to ensure safety [46]. Figure 23 shows the required adhesion coefficient according to these three categories. Requirements of the adhesion coefficient from other countries/cities are shown in Table 2 [39].

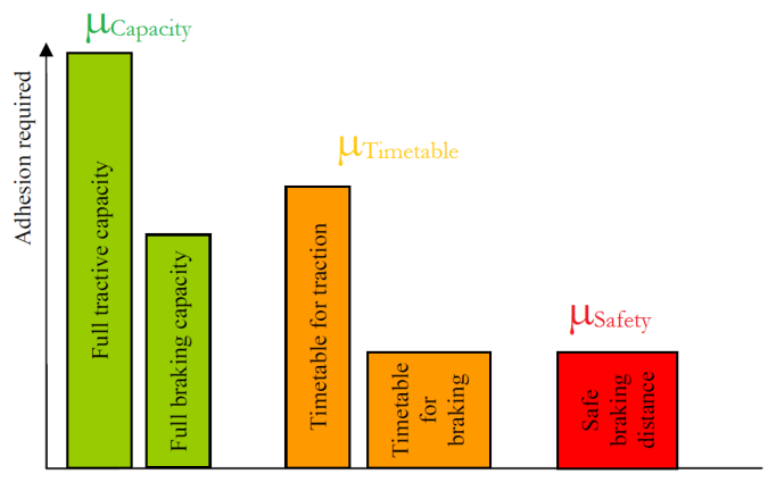

Figure 23. Common types of adhesion requirements in railway transportation [46]. (the length of the bars is given in proportion to the maximum required adhesion coefficient in the Netherlands)

Table 2. Required adhesion coefficients. [39]

\begin{tabular}{|l|c|c|}
\hline & Adhesion coefficient for braking & Adhesion coefficient for traction \\
\hline Stockholm public transport & approximately 0.15 & 0.18 \\
\hline U.K. & 0.09 & 0.2 \\
\hline Netherlands & 0.07 & 0.17 \\
\hline
\end{tabular}

However, the wheel-rail interface is an open system meaning contaminants can enter the contact effecting friction levels and also adversely or favourably effecting wheel and rail damage such as wear and rolling contact fatigue. Serious problems are caused by poor adhesion, resulting from too low friction levels. Contaminants such as water, iron oxide and leaves; materials which are unintentionally present on the rail [36], should be distinguished from flange lubricants and friction modifiers, both of which are deliberately applied to the rail or wheel. All of the above can be termed "third-body

This paper was published in Vehicle System Dynamics; Special Issue: State of Art Papers of the $23^{\text {rd }}$ IAVSD in 2013. Online version: http://dx.doi.org/10.1080/00423114.2013.800215 
materials" [47] which form a third-body between the bulk materials of the wheel and rail. These thirdbodies are sometimes chemically bonded to the surfaces of the bulk materials (i.e. iron oxide and leaves). Therefore, in practice the actual materials which form the wheel-rail contact can be chemically different from the wheel and rail steels that form the actual wheel and rail as shown in Figure 24.

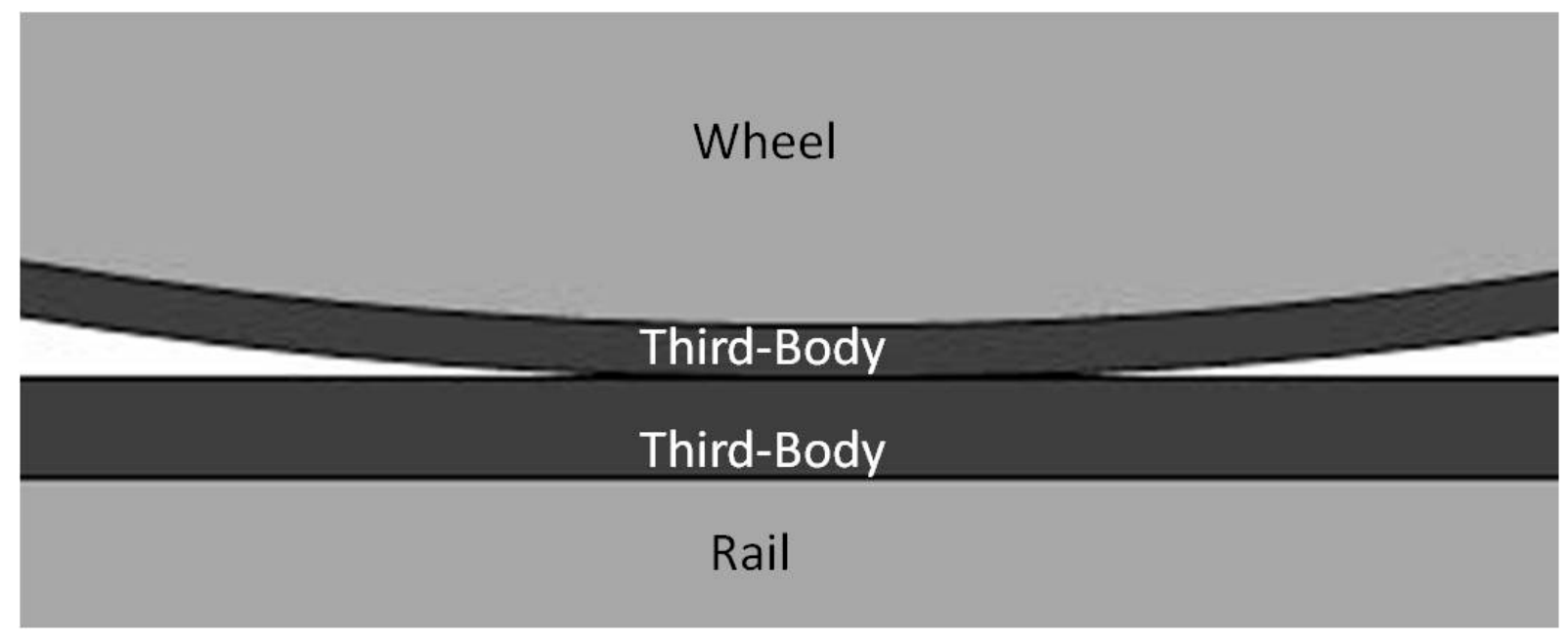

Figure 24. An illustration of the third-body layer between the bulk materials in the wheel-rail contact [36]

An example of the adhesion coefficient under various conditions is shown in Table. 3 [48]. For convenience, the effects of contaminants including oil lubricants will be discussed in this section while friction modifiers will be discussed in the next section.

Table 3. Examples of wheel-rail adhesion coefficients [48].

\begin{tabular}{|l|c|l|c|}
\hline Rail conditions & Adhesion coefficient & Rail conditions & Adhesion coefficient \\
\hline Dry and clean & $0.25-0.3$ & Moisture & $0.09-0.15$ \\
\hline Dry with sand & $0.25-0.33$ & Light snow & 0.10 \\
\hline Wet and clean & $0.18-0.20$ & Light snow with sand & 0.15 \\
\hline Wet with sand & $0.22-0.25$ & Wet leaves & 0.07 \\
\hline Greasy & $0.15-0.18$ & & \\
\hline
\end{tabular}

Water and oil can be found on the rail or wheel and both of them can reduce the adhesion coefficient if entrained into the contact. An investigation of the influence of water and oil on adhesion/friction was carried out by Beagley et al. [49, 50]. Results from a full scale test rig [51, 52] and field tests [53] indicate that the adhesion coefficient reduces significantly with increasing rolling speed under wet conditions while the adhesion coefficient does not change much with speeds though remains low under oil-lubricated conditions. Both full scale tests [52] and lab tests [54] have also found that water with a higher temperature has a higher adhesion coefficient than water at a lower temperature as shown in Figure 25.

This paper was published in Vehicle System Dynamics; Special Issue: State of Art Papers of the $23^{\text {rd }}$ IAVSD in 2013. Online version: $\underline{\text { http://dx.doi.org/10.1080/00423114.2013.800215 }}$ 
a )

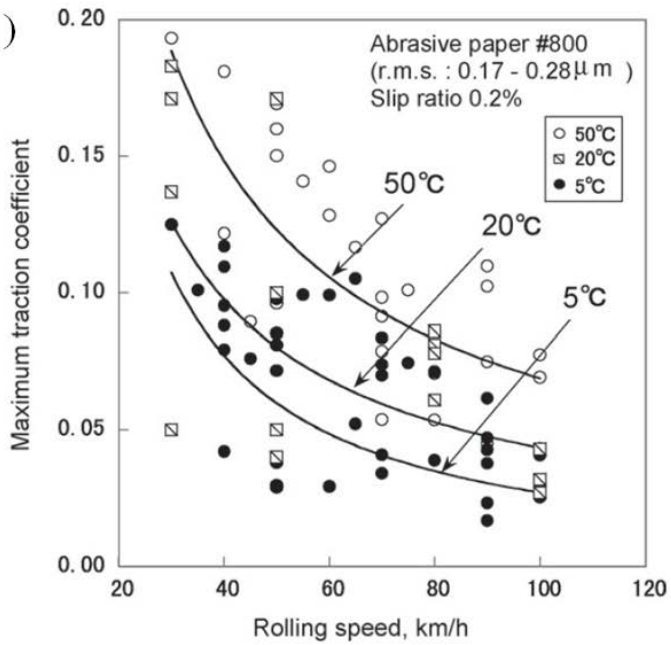

b )

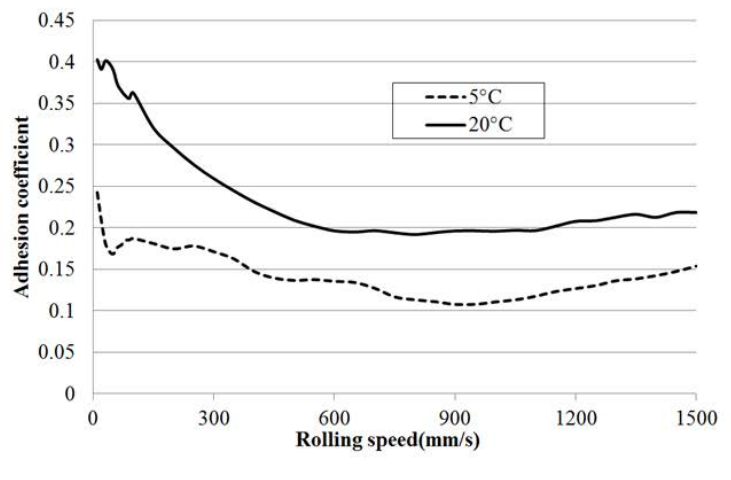

Figure 25. The influence of water temperature on the adhesion coefficient. a) was obtained from a full scale roller rig [52]; b) was obtained from a ball-on-disc machine [54].

The lubrication regime under oil and water contaminated contacts was discussed by Zhu et al. [54] using a ball-on-disc test rig showed that water can only form a very thin film compared to oil. Nakahara et al. [55] found that different oxides formed under wet conditions and research carried out in [56, 57] showed significant influence of oxide layers on the adhesion coefficient under water contamination. All of these indicate that in wet conditions, the mechanism of adhesion reduction is quite complicated in which the oxide layer or rust may have a large impact. Thus it is important to take weather conditions which affect oxidation, such as temperature and humidity [58, 59], into consideration. Lewis et.al [60] used at pin-on-disc rig to investigate the effect of humidity and temperature on a sliding contact with iron oxides and friction modifier mixtures. This study pointed out that when Magnetite (black oxide) is mixed with friction modifier the friction rises at a greater rate than when Haematite (red oxide) is present in the friction modifier. It was also found that increasing temperature has a decreasing effect on the friction with increasing oxide content. Moreover, the surface modification with the presence of FM is much greater at a high humidity condition than at a low humidity condition.

The effects of oil and water mixtures were studied using a twin disc test rig [61] (shown in Figure 26) and a wheel-rail simulation facility [62] (shown in Figure 27). Both of them found that it is the oil in the mixture that has a dominating effect in reducing adhesion/friction. Figure 27 shows that this seems to be true even when sand is present which is commonly used to increase adhesion under low adhesion conditions. The mixture of oil and wear debris was investigated by Beagley et al. [63]. He pointed out that in dry weather the debris helps maintain adhesion against the effects of oil while adhesion is reduced on the debris covered surfaces in humid conditions. Salt is commonly used in winter to combat against ice on European roads. This salt has been shown to find its way onto railway tracks at road/rail crossings. A study regarding salt and oxide was performed by Hardwick et al. [42]. Oxide reduces adhesion/friction significantly under wet conditions. The adhesion coefficient also decreases with salt solution and dry salt since the presence of Chlorine can increase oxidation. 


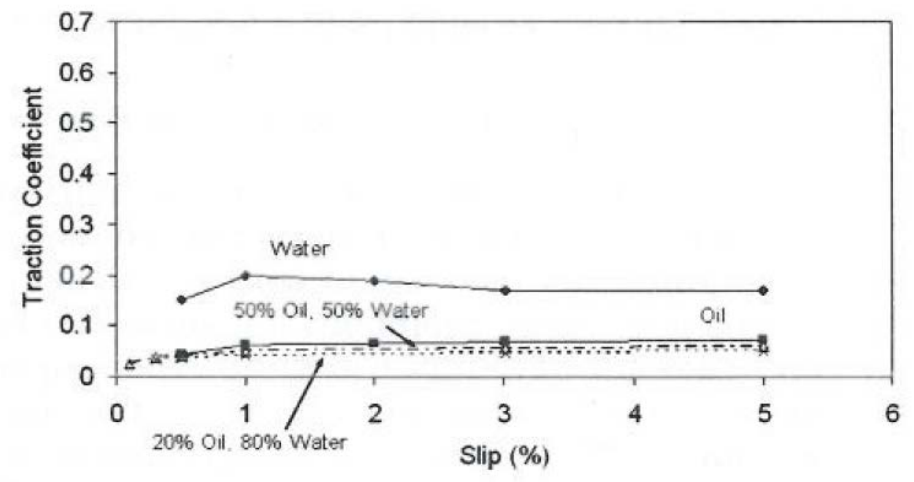

Figure 26. Creep curves for oil and water mixture tests obtained from a twin-disc test rig [61] with rolling speed at around $1 \mathrm{~m} / \mathrm{s}$
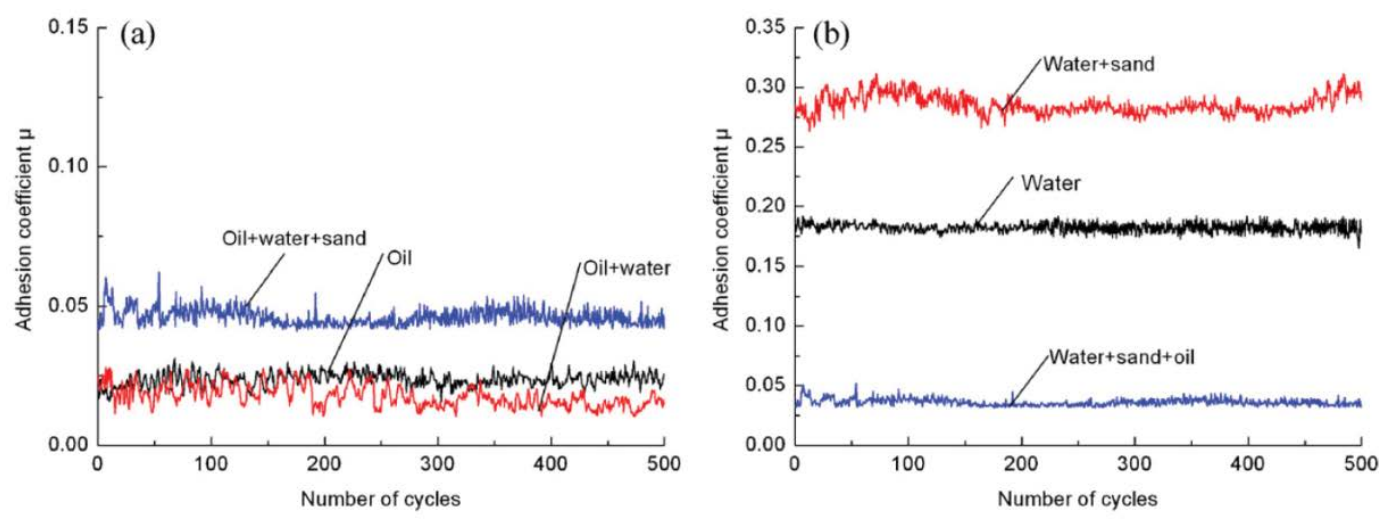

Figure 27. Graphs of adhesion coefficient versus number of cycles obtained from a wheel-rail simulation facility [62] with rolling speed at around $90 \mathrm{~km} \mathrm{~h}^{-1}$. a) effect of oil on adhesion coefficient; b) effect of water on adhesion coefficient

Rail services worldwide are also disturbed by crushed leaf layers on the rail head which can reduce the friction coefficient to below 0.1 [48]. According to Fulford [64], leaves don't have to fall precisely on the tracks but leaves which have fallen at the side of the line can be stirred up by the turbulence of a passing train coincidentally landing on the rail surface. The leaves are then crushed by passing wheels to form a charred/tarnished layer which is chemically bonded to the railhead. The costs associated with low adhesion of which leaves are thought to have a major contribution can be very high and are estimated to be in the region of $£ 50 \mathrm{~m}$ annually on the UK network alone [65, 66]. Leaf fall can also cause a lot disturbance to traffic on the network [45]. Research into leaf contamination and low adhesion has been carried out using various methods including actual trains [67], pin-on-disc [58, 68], twin-disc [69, 70] and ball-on-disc [71] test rigs. A comparison of these tests was discussed in [72], and is shown in Table 4. The results indicate that crushed leaves can reduce the friction coefficient but the friction coefficient decreases remarkably with the presence of the water or high humidity. Adhesion problems have even been reported on the track without any visible signs of a crushed leaf layer [68]. Extracted rail samples were cut from the field during five occasions including a period of leaf contamination and a period without leaf contamination. All of them were analysed and results indicated that there was a different chemical composition on the sample with a tarnished layer indicating a chemical reaction had taken place between the crushed leaves and the rail steel [72]. It was pointed out that with increased thickness of the oxide layer on the railhead surface the friction coefficient reduces [72] although no definitive relationship was found between leaf contamination thickness and the friction levels [64]. 
Table 4. Comparison of leaf contamination by a variety of test methods [72]

\begin{tabular}{|c|c|c|c|c|c|}
\hline Authors & $\begin{array}{l}\text { Olofsson and } \\
\text { Sundvall }[58] ; \\
\text { Olofsson }[68]\end{array}$ & $\begin{array}{l}\text { Gallardo- } \\
\text { Hernandez } \\
\text { and Lewis } \\
{[70]}\end{array}$ & Li et al. [69] & Cann [71] & $\begin{array}{l}\text { Arias-Cuevas } \\
\text { and Li [67] }\end{array}$ \\
\hline Test apparatus & Pin-on-disc & Twin disc & Twin disc & $\begin{array}{l}\text { Mini traction } \\
\text { machine }\end{array}$ & $\begin{array}{l}\text { Field tests } \\
\text { using } \\
\text { locomotives }\end{array}$ \\
\hline Load/pressure & $\begin{array}{l}800 \mathrm{MPa} \\
1.1 \mathrm{GPa}\end{array}$ & 1.5GPa & $1.2 \mathrm{GPa}$ & $1 \mathrm{GPa}$ & $\begin{array}{l}\text { Axle load } 15 t \\
\text { and } 17 t\end{array}$ \\
\hline Rolling speed & $\begin{array}{l}0.1 \mathrm{~m} \mathrm{~s}^{-1} \text { (pure } \\
\text { sliding) }\end{array}$ & 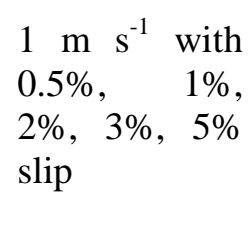 & $\begin{array}{l}1 \mathrm{~m} \mathrm{~s}^{-1} \text { with } \\
0.5 \%, 1 \%, 2 \% \\
\text { slip }\end{array}$ & $\begin{array}{l}0.02-1 \mathrm{~m} \mathrm{~s}^{-1} \\
\text { with } 1 \% \text { and } \\
50 \% \text { slip }\end{array}$ & $\begin{array}{l}22 \pm 2 \mathrm{kmh}^{-1} \\
\text { to } 27 \pm 2 \mathrm{kmh}^{-} \\
1 \text { (around } 5.6 \\
\mathrm{~m} \mathrm{~s}^{-1} \text { to } 8.1 \mathrm{~m} \\
\mathrm{~s}^{-1} \text { ) }\end{array}$ \\
\hline $\begin{array}{l}\text { Test } \\
\text { conditions }\end{array}$ & Dry/oil/humidity & Dry/wet & Dry & Wet & Dry/wet \\
\hline $\begin{array}{l}\text { Preparing the } \\
\text { leaf } \\
\text { contaminated } \\
\text { layer }\end{array}$ & $\begin{array}{l}\text { Crush leaves in } \\
\text { the mortar then } \\
\text { roll them eight } \\
\text { times using a } \\
\text { roller. }\end{array}$ & $\begin{array}{l}\text { Leaves were } \\
\text { feed through } \\
\text { the contact } \\
\text { between discs } \\
\text { with the help } \\
\text { of suction. }\end{array}$ & $\begin{array}{l}\text { Leaves were } \\
\text { defrosted and } \\
\text { cut into small } \\
\text { pieces. }\end{array}$ & $\begin{array}{l}\text { Chop leaves } \\
\text { into } 5 \mathrm{~mm}^{2} \\
\text { samples and } \\
\text { soaked in the } \\
\text { water for 1- } \\
\text { 15days. }\end{array}$ & $\begin{array}{l}\text { Leaves were } \\
\text { placed on the } \\
\text { rail top with } \\
\text { the help of } \\
\text { water. EMU } \\
\text { passed over } \\
\text { the leaves. }\end{array}$ \\
\hline $\begin{array}{l}\text { Range of the } \\
\text { adhesion } \\
\text { coefficient }\end{array}$ & $0.07-0.25$ & $0.01-0.06$ & $\begin{array}{l}0.01-0.04 \\
\text { with } 0.5 \% \text { slip }\end{array}$ & $\begin{array}{l}0.01-0.07 \\
\text { using soaked } \\
\text { leaf samples; } \\
0.04-0.14 \\
\text { using water- } \\
\text { soluble leaf } \\
\text { extracts. }\end{array}$ & $\begin{array}{l}0.12-0.22 \\
\text { (average); } \\
0.005-0.05 \\
\text { (minimum) }\end{array}$ \\
\hline
\end{tabular}

\subsection{Measures to improve wheel-rail adhesion}

Improvement of wheel-rail adhesion can be achieved by: controlling longitudinal creep or by modifying the friction level between the wheel and rail. The creep curve in Figure 22 shows the relationship between the adhesion coefficient and creep. Depending on the requirement, a targeted adhesion coefficient can be reached by controlling the creep. If the contact is contaminated and the required adhesion is high, the creep should be very accurately controlled in order to gain maximum adhesion coefficient which is the saturation point in Figure 22. In the vehicle, usually a slip control technique is used for this purpose [41].

On the other hand the friction coefficient is an essential factor in influencing available adhesion. If the friction coefficient is too low, the wheel tends to slip under acceleration or lock under braking; causing damage to both wheel and rail due to high sliding speeds and heat generated at the interface. If friction 
is too high this can also lead to excessive wear. Friction management can be used in order to maintain the friction coefficient between the wheel and the rail within desirable levels. The ideal friction coefficient for heavy haul traffic is shown in Figure 28. Friction modifiers are thus applied to the wheel-rail interface in order to achieve a target friction coefficient. According to Kalousek and Magel [73], they are divided into three categories:

Low coefficient friction modifier (LCF)/lubricant in the wheel flange/rail gauge contact;

High positive friction modifier (HPF) in the wheel tread/rail head contact;

Very high positive friction modifier (VHPF) for locomotives.

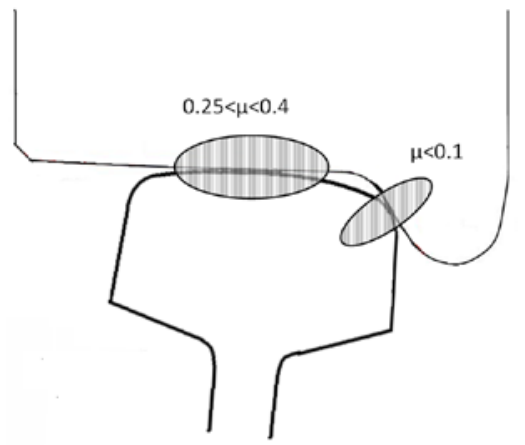

Figure 28. Ideal friction coefficients in the wheel-rail contact for heavy haul traffic [39].

LCF can be in the form of solids, oils or greases. These lubricants are usually applied to the hi-rail when the train enters a curve and the wheel-rail contact shifts from the railhead/wheel tread to the rail gauge/wheel flange. Since the wheel flange/rail gauge contact conditions are quite severe, the application of LCF reduces the friction coefficient thus reducing wear and noise. It is vitally important however, that these LCFs do not migrate onto the railhead as friction levels in this region need to be kept relatively high. This is where solid LCFs have an advantage as a solid layer builds up on the wheel flange and rail gauge. The benefits of rail lubricants on reducing the friction coefficient are discussed in Olofsson and Telliskivi [74] from filed measurements and Sundh and Olofsson [75] from laboratory tests.

The application of HPF is mainly to reduce short pitch corrugation and squeal by introducing a positive slope after the saturation point on the creep curve as shown in Figure 29 [76]. The positive slope is introduced in order to avoid stick-slip oscillations. HPFMs are used to keep the friction/adhesion in a desired range which is beneficial for reducing wear and noise and are used on railhead.

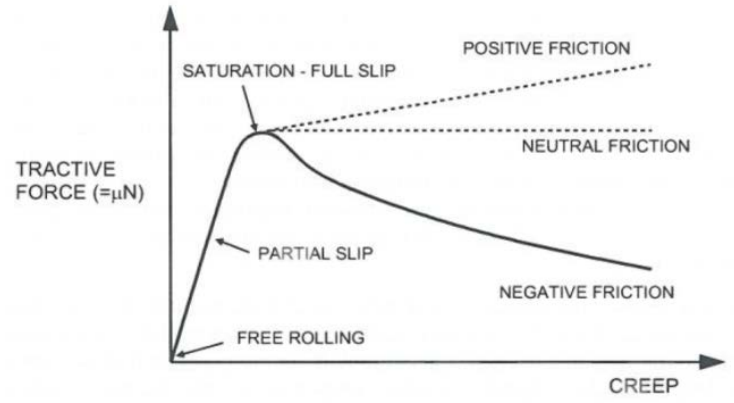

Figure 29. Behaviour of friction modifier [76]. 
Due to its effectiveness and easy-application, sand is the main VHPF used worldwide. Unlike HPFs, VHPFs are used to restore adhesion under adhesion loss conditions. These adhesion loss situations are usually short lived and in order to restore safe operation of a locomotive quickly high wear rates [77] and electrical isolation which can be caused by these products can be tolerated [78]. Arias-Cuevas et al. $[79,80]$ compared four types of sands with different grain sizes using a combination of laboratory (twin-disc) testing and field testing. Both test methods showed that medium sized sand particles are the most effective for adhesion recovery. Besides sand, two other adhesion enhancers with different components are discussed by Li et al. [81] and Arias-Cuevas et al. [82]. It was pointed out that the friction modifier having small soft particles performs better under wet conditions while the friction modifier having large hard particles is better at removing leaf layers with a sacrifice of increased surface damage.

The ability of VHPF's to remove crushed leaf layers from the rail is also important. Olofsson [68] proposed a multi-layer model pointing out that leaves form both a coated slippery layer and a chemically reacted, easily sheared surface layer on the rail bulk material. Removal of only the coated slippery layer is not enough to restore friction levels. A number of methods are used to combat adhesion problems due to leaf contamination including: sand [72, 80], Sandite (a mixture of sand and aluminum oxide particles), high-pressure water jetting, high-powered lasers [70] and a magnetic track brake [83]. However, leaf contamination on the rail is very localized and the contaminated depth varies. It is therefore difficult to know how much material needs to be removed from the rail head at each affected section in order to recover friction.

Surface topography can be another factor influencing wheel-rail adhesion especially under wet conditions. Chen et al. [52] found that surface roughness and surface orientation can also affect adhesion as indicated in Figure 30. In a scaled laboratory test rig, Zhu et al. [54] also found rough surfaces have a higher adhesion coefficient than smoother surfaces under wet conditions, however, this phenomenon is not found under oil-lubricated conditions. A possible explanation for this is that smoother surfaces allow water to shift from the boundary lubrication regime to the mixed lubrication regime in which the fluid forms a discontinuous film to take parts of the normal load thus reducing adhesion coefficient. Oil on the other hand has a much higher viscosity compared to water and therefore an oil lubricated contact operating under the same conditions should be in a mixed lubrication regime and is less likely to be influenced by surface roughness. Tracks with rough surfaces can prevent significant adhesion loss when tracks are wet.
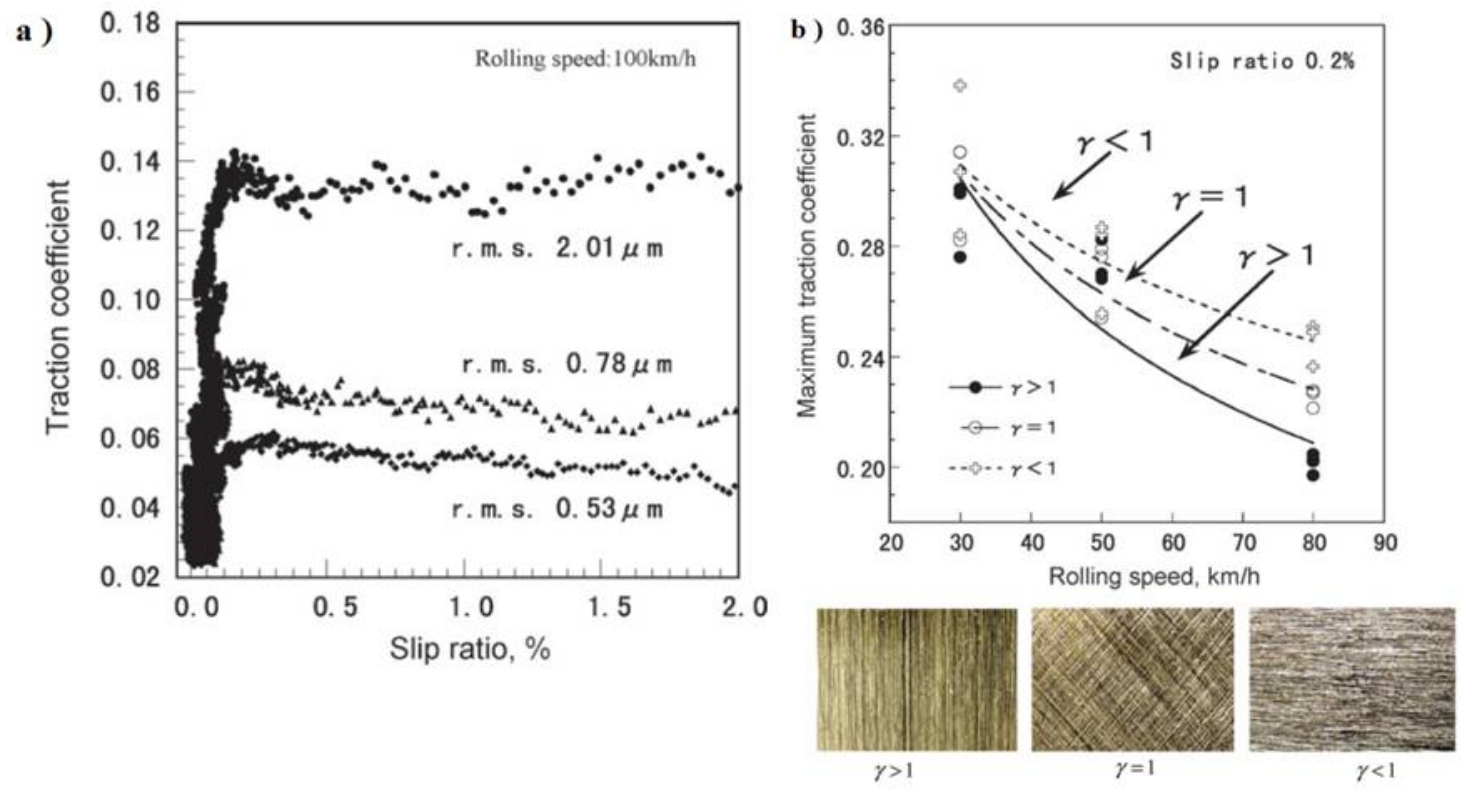

Figure 30. The influence of (a) surface roughness and (b) surface orientation on the adhesion coefficient. [52] r.m.s (root mean square) refers to roughness parameter $\mathrm{R}_{\mathrm{q}}$ 


\subsection{Adhesion modeling}

Classic contact models, such as CONTACT and FASTSIM, were developed under the assumption of rolling with dry friction. Thus, they are valid and mainly used to investigate the wheel-rail contact under dry and clean contact conditions. Recently a numerical model was developed to study wheel-rail adhesion under contaminated conditions. However, due to the complexity of some types of wheel-rail contamination, the adhesion model accounted only for water and oil lubricated conditions [84-87]. These numerical models were based on some simplifications such as: an infinite half space, static conditions and a constant friction coefficient which is fully used by the adhesion in the longitudinal direction. Based on the models, the influence of surface topography, fluid properties and rolling speed on the adhesion coefficient were investigated and found to be in accordance with testing results. Nevertheless, some other important factors, such as plasticity and flash temperature, need to be studied further. The main purpose of numerical modelling is not to be applied directly to multi-body simulations but to study the influencing factors in order to improve current fast models for dynamic simulation. This method can take many factors into consideration to study their effects separately with the limitation that only water and oil are able to be modelled numerically. Other third body layers can be modelled with the help of both laboratory or field testing and existing theories.

Another way to improve the current fast model is to use empirical models which are obtained from testing, see Zhang et al. [51] and Polach [88]. Zhang et al [51] provides measurement results on a roller rig and apply a modification of FASTSIM to achieve better results with measurements. The method by Polach is not a modification of FASTSIM, but a semi-physical method based on Kalker's linear theory. It is used in several commercial multi-body simulation tools. Polach [88] presents an extension of the Polach's method for simulations at large creep on adhesion limit. The required additional parameters are based on measurements on locomotives. This solution provided better agreement with measurements at high traction creepage than other methods used in multi-body simulation tools used the results from full scale roller rig and field measurements then modified some parameters in Kalker's FASTSIM code. However, the investigation of a single factor which may affect wheel-rail adhesion becomes difficult and the actual mechanism behind adhesion loss remains unknown.

\section{Concluding remarks and future trends}

This review of some of the issues arising from/affecting the wheel-rail contact highlights the high complexity of the system and the large influence third body materials can have, both negative and positive. These effects are not incorporated well at the moment into modelling tools used for wheelrail contact assessment.

The basic rolling contact under clean conditions or without any contaminants is well studied. The research focus has shifted to the contact with the presence of a third body between the wheel and rail. Liquids, such as water and oil, can form a boundary or mixed lubricating film to reduce the adhesion. The amount of reduction depends on the surface topography, liquid temperature and rolling speed. In addition, oxidation or hydrated oxidation is also an important issue when the humidity is high or the contact is lubricated by water. Since the generation and the duration are hard to measure, the oxidation or hydrated oxidation is not well investigated. There is a lot of work to do in this area to improve the basic knowledge. Leaves, which can become chemically reacted with the rail, can form a charred/tarnished layer on the rail surface which is hard to remove and causes a large reduction in adhesion . The leaves should be removed from the track before they form a slippery layer. If the slippery layer is formed, it should be removed as soon as possible before it forms a thick oxide layer. Applying friction modifier is an efficient way to control the adhesion as required. Sands, as adhesion enhancer, can recover adhesion but increases wear. The size and the hardness of sand particles need to be optimised before using them.

To develop a model which can predict the adhesion coefficient under various conditions is the goal which needs the contribution from both dynamic modellers and tribologists. The model is based on investigations from two aspects: the adhesion loss mechanism to understand how adhesion is reduced

This paper was published in Vehicle System Dynamics; Special Issue: State of Art Papers of the 23 ${ }^{\text {rd }}$ IAVSD in 2013. Online version: http://dx.doi.org/10.1080/00423114.2013.800215 
due to different contaminants and data of the friction coefficient measured under various conditions. For the latest research, the trend is to apply the research results from the laboratory to analytical models in order to model the wheel-rail contact with the presence of a third body layer. The work presented by Vollebregt [89] and Meierhofer et al. [90] showed the latest developments. However, in order to be used in multi-body simulations, the work should be generalised into some parameters which can be applied to software packages such as FASTSIM.

Various methods for reducing wear in the wheel-rail contact have been reviewed by Braghin et al. [91]. They noted that optimizing the wheel profile and applying friction modifiers on wheels or rails were successfully implemented and reported by various researchers. Optimizing the bogie design is also another suggested solution. These kinds of optimization are intended to minimize creep forces and increase running performance. These objectives can be achieved by either reducing primary suspension stiffness (Andersson et al., [92]) or adding new systems, such as active secondary suspension (Diana et al., [93]).

Different filtering system has been suggested and discussed as a method for reducing exposure to particles in enclosed environments. Tokarek and Bernis [94] investigated the practicality and effect of using an electrostatic precipitator in a Paris subway station. They predicted that the particle concentration could be halved by the application of several electrostatic precipitators. Washing to remove deposited particles to inhibit suspension of particles has been suggested as a mitigation measure. However, tests performed have resulted in uninterestingly low or no effects on concentration levels (Johansson[95]; Gustavsson et al., [96]).

There is lack of simulation methodology for non-exhaust emissions from rail transport and further research is necessary in order to develop theories, models and simulation tools that can be implemented in multibody simulation tools as GENSYS: There are however some initiatives as Abbasi et al. [97] suggested a method for measuring the airborne wear particle emission rate (AWPER) from wheel-rail contacts and braking mate. It was suggested that this method be used by governmental organizations to force manufacturers to consider the wear particle emission rates of their products and to optimize their products in accordance with the proposed regulations so as to minimize related emissions. Olofsson, Olander and Jansson [98] proposed as airborne particle coefficient that could be used to create particle coefficient maps in the same manner as the wear map presented in Figure 7.

It must be noted that particle emission from rail transport has been much less studied than from road transport. The progress of toxicity studies in road transport can be used as a basis for future studies of rail transport emission. For instance, WearTox , an ongoing project by the Swedish National Road and Transport Research Institute (VTI), is focusing on the toxicity of car brake pad particles and pavement particles (VTI, ,[99]). Similar studies to investigate the toxicity of braking materials particles or wheel-rail particles will shed light in this context.

\section{References}

[1] R. Nilsson, Wheel/Rail wear and surface cracks, Licentiate Thesis, KTH, Stockholm 2003.

[2] J.A. Williams, Wear modelling, analytical, computing and mapping: a continuum mechanics approach. Wear, 225-229 (1999) pp. 1-17.

[3] U. Olofsson, S. Andersson, and S. Björklund, Simulation of mild wear in boundary lubricated spherical roller thrust bearings. Wear 241 (200) pp. 180-185.

[4] J.L. Sullivan, Boundary lubrication and oxidational wear. Journal of Physics \& Applied Physics. 19 (1986) pp. 1999-2011.

[5] U. Olofsson and G. Svedberg, Low concentration level contaminant-related wear in sliding and rolling contacts, $2^{\text {nd }}$ World Tribology Congress Vienna Sept. 03-07 2001.

This paper was published in Vehicle System Dynamics; Special Issue: State of Art Papers of the $23^{\text {rd }}$ IAVSD in 2013. Online version: http://dx.doi.org/10.1080/00423114.2013.800215 
[6] R. Lewis and R. Dwyer-Joyce, Wear mechanisms and transitions in railway wheel steels, Journal of Engineering Tribology, Proceedings of the IMechE Part J, Vol. 218, pp467-478

[7] R. Lewis and U. Olofsson, Mapping Rail Wear Regimes and Transitions, Wear, Vol. 257, No. 79, (2004) pp721-729.

[8] S. Andersson and E. Salas-Russo, The influence of surface roughness and oil viscosity on the transition in mixed lubricated sliding steel contacts. Wear. 174 (1994) pp. 71-79.

[9] S. Dizdar, Wear transition of a lubricated sliding steel contact as a function of surface texture anisotropy and formation of boundary layers. Wear. 237 (2000) pp. 205-210.

[10] U. Olofsson and T. Telliskivi, Wear, friction and plastic deformation of two rail steels - full scale test and laboratory study, Wear 254 (2003) pp. 80-93.

[11] U. Olofsson and R. Nilsson, Surface cracks and wear of rail: a full scale test and laboratory study, Journal of Rail and Rapid Transit 216 (2002) pp. 249-264.

[12] P. Waara, Wear reduction performance of rail flange lubrication. Licentiate thesis LTU, Mechanical Engineering, 2000.

[13] F. Cantara, Investigation of wheel flange wear on the Santander FEVE Rail - a case study. Wear 162 (1993), pp. 975-979.

[14] A. Rovira, A. Roda, R. Lewis and M.B. Marshall, Application of Fastsim with variable coefficient of friction using twin disc experimental measurements. Wear 274-275 (2012) pp. 109-126.

[15] C. Hardwick, R. Lewis and D.T. Eadie, Wheel and rail wear - understanding the effect of third body materials. Proceedings of CM2012 9th International Conference on Contact Mechanics and Wear of Rail/Wheel Systems, Chengdu, China, Aug. 26-30 pp. 394-401.

[16] S. Engel, Reibungs- und Erdmudungsverhalten des Rad-Schiene-System mit und ohne Schmierung. Ph D. thesis Otto von Guericke Universität Magdeburg, 2002

[17] A.J. Perz-Unzueta and J. Beynon, Microstructure and wear resistance of perlitic rail steels, Wear. 162 (1993) 173-182.

[18] J.E. Garnham and J.H. Beynon, Dry rolling-sliding wear of bainitic and perlitic steels. Wear. 157 (1992) 81-109.

[19] S. Mitao, H. Yokoyama and S. Yamamoto, High strength bainitic steel rails for heavy haul railways with superior damage resistance, IHHA'99 STS conference, Moscow, Russia.

[20] S. Abbasi, A. Jansson, U. Olofsson, U. Sellgren, Particle emissions from rail traffic: A literature review, Critical Reviews in Environmental Science and Technology, In press (http://dx.doi.org/10.1080/10643389.2012.685348).

[21] L. Olander and A. Jansson, Tunnlar och hälsorisker (Tunnels and health risks, in Swedish). Arbete, människa, miljö \& Nordisk ergonomi, 1997(2), 114-120.

[22] E. Uherek, T. Halenka, J. Borken-Kleefeld, Y. Balkanski, T. Berntsen, C. Borrego, M. Gauss, P. Hoor, K. Juda-Rezler, J. Lelieveld, D. Melas, K. Rypdal and S. Schmid, Transport impacts on atmosphere and climate: Land transport. Atmos. Environ. 44, 2010, 4772-4816.

[23] J.S. Fuglestvedt, K.P. Shine, T. Berntsen, J. Cook, D.S. Lee, A.D, Stenke, R.B. Skeie, G.J.M. Velders, and I.A. Waitz, Climate forcing from the transport sectors PNAS, 2008, 105, 454-458.

[24] S. Abbasi, U. Sellgren, U. Olofsson, Experiences of Studying Airborne Wear Particles from Road and Rail Transport, Aerosol and Air Quality Research, In press.(doi: 10.4209/aaqr.2012.10.0295)

[25] EU Directive 2008/50/EC, 2008. On ambient air quality and cleaner air for Europe. Available at http://eurlex.europa.eu/LexUriServ/LexUriServ.do?uri=OJ:L:2008:152:0001:0044:EN:PDF (accessed 21 February 2012). 
[26] EPA NAAQS, 2012. National Ambient Air Quality Standards. Available at http://www.epa.gov/pm/2012/decfsoverview.pdf (accessed 15 December 2012).

[27] J. Sundh and U. Olofsson, Relating contact temperature and wear transitions in a wheel-rail contact, Wear $271(1-2)$, pp. 78-85

[28] U. Olofsson, L. Olander and A. Jansson, A study of airborne wear particles generated from a sliding contact, (2009) Journal of Tribology, 131 (4), pp. 1-4.

[29] S. Abbasi, U. Olofsson, Y. Zhu and U. Sellgren, Pin-on-disc study of the effects of railway friction modifiers on airborne wear particles from wheel-rail contact, (2013) Tribology International, 60, pp. 136-139.

[30] E. Fridell, M. Ferm, A. Björk and A. Ekberg, On-board measurement of particulate matter emissions from a passenger train. Journal of Rail and Rapid Transit, 2011, 225, 99-106.

[31] S. Abbasi, A. Jansson, L. Olander, U. Olofsson, C. Larsson and U. Sellgren, A field test study of airborne wear particles from a running regional train. Journal of Rail and Rapid Transit, 2012a, 226 (1), 95-109

[32] BS EN 13144:2003, Metallic and Other Inorganic Coatings - Method for Quantitative Measurement of Adhesion by Tensile Test

[33] BS EN ISO 4624:2003, Paints and Varnishes - Pull-off Test for Adhesion

[34] S R. Lewis, Measurement, Control and Enhancement of Friction/Traction in a Simulated Wheel/Rail Contact, Doctorial Thesis, University of Sheffield, UK, 2011

[35] D I. Fletcher and S. R. Lewis, Creep Curve Measurement to Support Wear and Adhesion Modelling, using a Continuously Variable Creep Twin Disc Machine, Wear 298-299 (2013), 5765.

[36] R. Lewis and U. Olofsson, Wheel-rail interface handbook, Woodhead Publishing Limited, Cambridge, UK, 2009.

[37] H. Czichos, Presentation of Friction and Wear Data. In Blau, P.J. (ed.), Friction Lubrication and Wear Technology, ASM Handbook, 18, ASM International, Materials Park, OH, USA. pp489493

[38] J. Williams, Engineering Tribology. Cambridge, UK, Cambridge University Press

[39] Y. Zhu, Adhesion in the wheel-rail contact under contaminated conditions, Licentiate thesis, KTH Machine design, 2011.

[40] J.J Kalker, Wheel-rail rolling contact theory, Wear 144 (1-2) (1991), pp. 243-261.

[41] E. Andersson and M. Berg, Spårfordonsteknik Rail vehicle technology, KTH.

[42] C. Hardwick, R. Lewis and U. Olofsson, Low adhesion due to oxide formation in the presence of $\mathrm{NaCl}$, Proceedings of 9th International Conference on Contact Mechanics and Wear of Rail/Wheel Systems (CM2012), Chengdu, China, Aug 27-30, 2012

[43] I.M. Hutchings, Tribology, Edward Arnold, London, 1992.

[44] H. Harrison, T. McCanney and J. Cotter, Recent developments in coefficient of friction measurements at rail/wheel interface, Wear 253 (2002), pp. 114-123.

[45] R. Lewis, S. Lewis, Y. Zhu, S. Abbasi and U. Olofsson, The modification of a slip resistance meter for measurement of railhead adhesion, Proc. Inst. Mech. Eng. F, J. Rail Rapid Transit 227 (2) (2013), pp. 196-200

[46] O. Arias-Cuevas, Low adhesion in the wheel-rail contact, Doctoral thesis, TUD, Delft, 2010. 
[47] R. Lewis, R.S. Dwyer-Joyce, S.R. Lewis, C. Hardwick and E.A. Gallardo-Hernandez, Tribology of the wheel-rail contact: The effect of third body materials, International Journal of Railway Technology 1 (1) (2012), pp. 167-194

[48] D.F. Moore, Principles and Applications of Tribology, Elsevier, Amsterdam (1998)

[49] T.M. Beagley, I.J. Mcewen and C. Pritchard, Wheel/rail adhesion: boundary lubrication by oily fluids, Wear 31 (1975), pp. 77-88.

[50] T.M. Beagley and C. Pritchard, Wheel/rail adhesion: the overriding influence of water, Wear 35 (1975), pp. 299-313.

[51] W. Zhang, J. Chen, X. Wu and X. Jin, Wheel/rail adhesion and analysis by using full scale roller rig, Wear 253 (2002), pp. 82-88.

[52] H. Chen, T. Ban, M. Ishida and T. Nakahara, Experimental investigation of influential factors on adhesion between wheel and rail under wet condition, Wear 265 (2008), pp 1504-1511.

[53] T. Ohyama, Tribological studies on adhesion phenomena between wheel and rail at high speeds, Wear 144 (1991), pp 263-275.

[54] Y. Zhu, U. Olofsson and K. Persson, Investigation of influential factors on wheel-rail adhesion using mini traction machine, Wear (292-293) (2012), pp. 218-231.

[55] T. Nakahara, K-S. Baek, H. Chen and M. Ishida, Relationship between surface oxide layer and transient traction characteristics for two steel rollers under unlubricated and water lubricated conditions, Wear 271 (2011), pp. 25-31.

[56] J. Suzumura, Y. Sone, A. Ishizaki, D. Yamashita, Y. Nakajima and M. Ishida, In situ X-ray analytical study on the alternation process of iron oxide layers at the railhead surface while under railway traffic, Wear 271 (2011), pp. 47-53,

[57] K. Ohno and Y. Ogawa, RTRI Rep., No. A-83-70, 1983 (in Japanese),

[58] U. Olofsson and K. Sundvall, Influence of leaf, humidity and applied lubrication on friction in the wheel-rail contact: pin-on-disc experiments, Proc. Inst. Mech. Eng. F, J. Rail Rapid Transit 218 (3), 2004, pp. 235-242,

[59] O. Hayashi, T. Nomura and K. Nagase, Influence of atmospheric conditions upon adhesion between rails and running wheels, Transactions of Japan Society of Mechanical Engineers, Part C 63 (606), 566-571 (in Japanese),

[60] S. Lewis, R. Lewis, U. Olofsson, D.T. Eadie, J. Cotter and X. Lu, Effect of humidity, temperature and railhead contamination on the performance of friction modifiers: Pin-on-disk study, Article in press, Proc. Inst. Mech. Eng. F, J. Rail Rapid Transit 218 (3), 2013, pp. 235-242,

[61] R Lewis, E.A. Gallardo-Hernandez, T. Hilton and T. Armitage, Effect of oil and water mixtures on adhesion in the wheel/rail contact, Proc. Inst. Mech. Eng. F, J. Rail Rapid Transit 223 (3), 2009, pp. 275-283,

[62] W.J. Wang, H.F. Zhang, H.Y. Wang, Q.Y. Liu and M.H. Zhu, Study on the adhesion behaviour of wheel/rail under oil, water and sanding conditions, Wear 271 (2011), pp. 2693-2698,

[63] T.M. Beagley, I.J. Mcewen and C. Pritchard, Wheel/rail adhesion: the influence of railhead debris, Wear 33 (1975), pp 141-152,

[64] C.R. Fulford, Review of Low Adhesion Research, Rail Safety and Standards Board, London, UK, 2004.

[65] L. Forslöv, Wheel slip due to leaf contamination, Swedish National Rail Administration TM 1996 03 19, Borlänge, Sweden, 1996.

[66] Managing low adhesion, Report published by the Adhesion Working Group, UK, (September 2001).

This paper was published in Vehicle System Dynamics; Special Issue: State of Art Papers of the $23^{\text {rd }}$ IAVSD in 2013.

Online version: http://dx.doi.org/10.1080/00423114.2013.800215 
[67] O. Arias-Cuevas and Z. Li, Field investigations on the adhesion recovery in leaf contaminated wheel-rail contacts with locomotive. Proc. Inst. Mech. Eng. F, J. Rail Rapid Transit 225 (2011), pp. 443-456.

[68] U. Olofsson, A multi-layer model of low adhesion between railway wheel and rail, Proc. Inst. Mech. Eng. F, J. Rail Rapid Transit 221 (2007), pp. 385-389.

[69] Z. Li, O. Arias-Cuevas, R. Lewis and E.A. Gallardo-Hernandez, Rolling-sliding laboratory tests of friction modifiers in leaf contaminated wheel-rail contacts, Tribology Letters 33 (2009), pp. 97-109.

[70] E.A. Gallardo-Hernandez and R. Lewis, Twin disc assessment of wheel/rail adhesion, Wear 265 (2008), pp. 1309-1316.

[71] P.M. Cann, The "leaves on the line" problem: a study of leaf residue film formation and lubricity under laboratory test conditions, Tribology Letters 24 (2006), pp. 151-158.

[72] Y. Zhu, U. Olofsson and R. Nilsson, A field test study of leaf contamination on the rail head surfaces, Proc. Inst. Mech. Eng. F, J. Rail Rapid Transit, Article in press. (] doi:10.1177/0954409712464860)

[73] J. Kalousek and E. Magel, Modifying and managing friction, Railway track and structures 93 (5) 1997, 31-36.

[74] U. Olofsson and T. Telliskivi, Wear, friction and plastic deformation of two rail steels: full-scale test and laboratory study, Wear 254 (2003), pp. 80-93.

[75] J. Sundh and U. Olofsson, Seizure mechanisms of wheel-rail contacts under lubricated conditions using a transient ball-on-disc test method, Tribology International 41 (2008), pp. 867-874.

[76] D.T. Eadie, J. Kaloesek and K.C. Chiddick, The role of high positive friction (HPF) modifier in the control of short pitch corrugation and related phenomena, Wear 253 (2002), pp. 185-192.

[77] R. Lewis and R.-S. Dwyer-Joyce, Wear at the wheel/rail interface when sanding is used to increase adhesion, Proc. Inst. Mech. Eng. F, J. Rail Rapid Transit, 220 (1) (2003), pp. 29-41.

[78] R. Lewis, R. S. Dwyer-Joyce and J. Lewis, Disc machine study of contact isolation during railway track sanding, Proc. Inst. Mech. Eng. F, J. Rail Rapid Transit 217 (2003), pp. 11-24.

[79] O. Arias-Cuevas, Z. Li and R. Lewis, A laboratory investigation on the influence of the particle size and slip during sanding on the adhesion and wear in the wheel-rail contact, Wear 271 (1-2) (2011), pp. 14-24.

[80] O. Arias-Cuevas and Z. Li, Field investigations into the adhesion recovery in leaf-contaminated wheel-rail contacts with locomotive sanders, Proc. Inst. Mech. Eng. F, J. Rail Rapid Transit, 225 (5) (2011), pp. 443-456.

[81] Z. Li, O. Arias-Cuevas, R. Lewis and E.A. Gallardo-Hernández, Rolling-sliding laboratory tests of friction modifiers in leaf contaminated wheel-rail contacts, Tribology Letters 33 (2) (2009), pp. 97-109.

[82] O. Arias-Cuevas, Z. Li, R. Lewis and E.A. Gallardo-Hernández, Rolling-sliding laboratory tests of friction modifiers in dry and wet wheel-rail contacts, Wear 268 (2-3) (2010), pp. 543-551.

[83] O. Arias-Cuevas and Z. Li, Field investigations into the performance of magnetic track brakes of an electrical multiple unit against slippery tracks, Part 1: Adhesion improvement, Proc. Inst. Mech. Eng. F, J. Rail Rapid Transit, 225(6) 2011, pp.613-636.

[84] H. Chen, T. Ban, M. Ishida and T. Nakahara, Adhesion between Rail/Wheel under Water Lubricated Contact, Wear 253(1-2) (2002), pp. 75-81.

[85] H. Chen, M. Ishida and T. Nakahara, Analysis of Adhesion under Wet Conditions for Threedimensional Contact Considering Surface Roughness, Wear 258 (7-8) (2005), pp. 1209-1216.

This paper was published in Vehicle System Dynamics; Special Issue: State of Art Papers of the $23^{\text {rd }}$ IAVSD in 2013. Online version: http://dx.doi.org/10.1080/00423114.2013.800215 
[86] C. Tomberger, P. Dietmaier, W. Sextro and K. Six, Friction in Wheel-Rail Contact: A Model Comprising Interfacial Fluids, Surface Roughness and Temperature, Wear 271 (1-2) (2011), pp. 2-12.

[87] Y. Zhu, U. Olofsson and A. Söderberg, Adhesion modeling in the wheel-rail contact under dry and lubricated conditions using measured 3D surfaces, Tribology International 61 (2013), pp. 110

[88] O. Polach, Creep forces in simulations of traction vehicles running on adhesion limit, Wear 258 (2005), pp. 992-1000

[89] E. A. H. Vollebregt, 100-fold speed-up of the normal contact problem and other recent developments in "CONTACT", Proceedings of 9th International Conference on Contact Mechanics and Wear of Rail/Wheel Systems (CM2012), Chengdu, China, Aug 27-30, 2012

[90] A. Meierhofer, C. Hardwick, R. Lewis, K. Sixa and P. Dietmaierc, Third body layer-experimental results and a model describing its influence on the traction coefficient, Proceedings of 9th International Conference on Contact Mechanics and Wear of Rail/Wheel Systems (CM2012), Chengdu, China, Aug 27-30, 2012

[91] F. Braghin, S. Bruni and R. Lewis, (2009). Railway wheel wear, in, R. Lewis, U. Olofsson (Eds.), Wheel-Rail Interface Handbook, Woodhead publishing limited, Cambridge, UK, 2009, pp. 172210.

[92] E. Andersson, M. Berg and S. Stichel, Rail Vehicle Dynamics. Division of Rail Vehicles, Department of Aeronautical and Vehicle Engineering, 2007, KTH, Stockholm.

[93] G. Diana, S. Bruni, F. Cheli and F. Resta, Active control of the running behavior of a railway vehicle, stability and curving performances. Vehicle System Dynamics Supplement 37, 2002, $157-170$.

[94] S. Tokarek and A. Bernis, An example of particle concentration reduction in Parisian subway stations by electrostatic precipitation. Environmental Technology 27(11), 2006, 1279-1287.

[95] C. Johansson and P.Å. Johansson, Particulate matter in the underground of Stockholm. Atmospheric Environment 37, 2003, 3-9.

[96] M. Gustafsson, G. Blomqvist, A. Dahl, A. Gudmunsson and E. Swietlicki, Inandningsbara partiklar i järnvägsmiljöer (Inhalable particles in railway environments). 2006, VTI Rapport 538. VTI, Linköping, Sweden (in Swedish).

[97] S. Abbasi, A. Jansson, L. Olander, U. Olofsson and U. Sellgren, A pin-on-disc study of the rate of airborne wear particle emissions from railway braking materials. Wear, 2012b, 284-285, 18-29.

[98] U. Olofsson, L. Olander, A. Jansson, Towards a model for the number of airborne particles generated from a sliding contact (2009) Wear, 267 (12), pp. 2252-2256.

[99] VTI, 2012, Wear ToxII, Air pollution and air quality (In Swedish) Available at: http://www.vti.se/sv/forskningsomraden/miljo/luftfororeningar-och-luftkvalitet/ $\quad$ (accessed 21 February 2012). 